\title{
Endosomal processing limits gene transfer to polarized airway epithelia by adeno-associated virus
}

\author{
Dongsheng Duan, ${ }^{1,2}$ Yongping Yue, ${ }^{1}$ Ziying Yan, ${ }^{1}$ Jusan Yang, ${ }^{1}$ and John F. Engelhardt ${ }^{1,2,3}$
}

${ }^{1}$ Department of Anatomy and Cell Biology,

${ }^{2}$ Center for Gene Therapy, and

${ }^{3}$ Department of Internal Medicine, College of Medicine, University of Iowa, Iowa City, Iowa, USA

Address correspondence to: John F. Engelhardt, Department of Anatomy and Cell Biology, University of Iowa School

of Medicine, 51 Newton Road, Room 1-101 Bowen Science Building, Iowa City, Iowa 52242, USA.

Phone: (319) 335-7753; Fax: (319) 335-7198; E-mail: john-engelhardt@uiowa.edu.

Received for publication September 1, 1999, and accepted in revised form April 13, 2000.

\begin{abstract}
The restriction of viral receptors and coreceptors to the basolateral surface of airway epithelial cells has been blamed for the inefficient transfer of viral vectors to the apical surface of this tissue. We now report, however, that differentiated human airway epithelia internalize rAAV type-2 virus efficiently from their apical surfaces, despite the absence of known adeno-associated virus-2 (AAV-2) receptors or coreceptors at these sites. The dramatically lower transduction efficiency of rAAV infection from the apical surface of airway cells appears to result instead from differences in endosomal processing and nuclear trafficking of apically or basolaterally internalized virions. AAV capsid proteins are ubiquitinated after endocytosis, and gene transfer can be significantly enhanced by proteasome or ubiquitin ligase inhibitors. Tripeptide proteasome inhibitors increased persistent rAAV gene delivery from the apical surface $>200$-fold, to a level nearly equivalent to that achieved with basolateral infection. In vivo application of proteasome inhibitor in mouse lung augmented rAAV gene transfer from undetectable levels to a mean of $10.4 \pm 1.6 \%$ of the epithelial cells in large bronchioles. Proteasome inhibitors also increased rAAV-2-mediated gene transfer to the liver tenfold, but they did not affect transduction of skeletal or cardiac muscle. These findings suggest that tissue-specific ubiquitination of viral capsid proteins interferes with rAAV-2 transduction and provides new approaches to circumvent this barrier for gene therapy of diseases such as cystic fibrosis.
\end{abstract}

J. Clin. Invest. 105:1573-1587 (2000).

\section{Introduction}

Cystic fibrosis $(\mathrm{CF})$ is the most common inherited disease in the Caucasian population. Because the pulmonary manifestations are the most important pathological changes associated with morbidity and mortality in patients with CF, the initial phases of gene therapy for this disorder will target the lung airway epithelium. Several viral vectors, including adenovirus, lentivirus, retrovirus, and adeno-associated virus (AAV), have been used in strategies conceived for functional correction of the cystic fibrosis transmembrane conductance regulator (CFTR) gene defect in patients with CF. The development of AAV as a gene therapy vehicle for treating $\mathrm{CF}$ has several unique advantages based on its viral biology. For example, wild-type AAV infections are known to occur in the respiratory epithelium but have no known associated pathology. Additionally, recombinant adeno-associated virus (rAAV) can infect nondividing cells, and its genome can exist in either integrated or episomal forms.

Unfortunately, fully differentiated airway epithelia are extremely resistant to infection from the apical surface, not only with rAAV-2, but also with all other types of viral vectors currently in use $(1,2)$. Several potential ratelimiting steps may be responsible for the observed resistance of the apical airway surface to infection with these viruses. These include viral binding, endocytosis, endosomal processing, nuclear transport, uncoating, gene conversion, and transcription and translation of gene products. Several clues have assisted researchers in understanding the rate-limiting steps for recombinant viral transduction in the airway. In the case of adenovirus, partitioning of viral receptors and coreceptors to basolateral surfaces has clearly been shown, at least in part, to contribute to low infectivity from the apical surface of the airway (2). Similarly, it is thought that the absence of viral receptors at the apical surface may also significantly limit transduction by retroviruses (1). Recently, the heparin sulfate proteoglycan receptor (3), and FGFR-1 (4) and $\alpha V \beta 5$ integrin (5) coreceptors for AAV-2, have been localized to the basolateral membrane of polarized airway epithelial cells $(6,7)$. This suggested that receptor abundance might also play a significant role in the low infectivity from the apical surface observed with rAAV-2. Studies on air-liquid interface cultures of primary human bronchial epithelia have demonstrated a 200-fold higher level of AAV-2 transduction from the basolateral, compared with apical membranes (6). Together with the fact that differentiated monolayers of airway cells are also resistant to AAV-2 infection (8), these studies suggest that aspects of either differentiation and/or polarity are responsible for reduced AAV infection from the apical surface. 
In general, two approaches have been used to circumvent the rate-limiting steps in viral vector transduction. These include manipulation of cell-surface receptors (9) and/or receptor ligands in the viral coat $(10,11)$. Alternative approaches have attempted to increase transgene expression by enhancing the molecular conversion of nonfunctional viral genomes to expressible forms, as in the case of $\operatorname{rAAV}(12,13)$, or by increasing transcription and translation efficiency by altering the transgene expression cassettes (14). In the present report, we demonstrate that AAV-2 binding and endocytosis at the apical membrane of airway epithelia are not the major rate-limiting factors in transduction of this tissue type. Rather, our studies show that endosomal processing and trafficking of virus to the nucleus are the major obstacles encountered after AAV-2 infection from the apical membrane of the airway. In contrast to basolateral infection, which leads to the efficient conversion of single-stranded AAV DNA to circular expressible genomes, apical infection gives rise to persistent, single-stranded viral DNA arrested in a transcriptionally inactive state for up to 50 days. At the molecular level, ubiquitination of the viral capsid appears to be a major barrier responsible for altering the efficiency of trafficking the virus to the nucleus, and/or nuclear processing events needed to convert its single-stranded DNA genome to a transcriptionally active state. Modulation of ubiquitin-proteasome pathways using either proteasome or ubiquitin ligase inhibitors increased the extent of rAAV gene transfer in airway epithelial. Such approaches will likely increase the utility of rAAV-2 for gene therapy, not only for $\mathrm{CF}$ and other airway diseases, but also for target tissues in which viral processing appears to be a rate-limiting event.

\section{Methods}

Primary culture of human bronchial epithelia and reagents utilized. Primary human airway epithelial cells were collected by enzymatic digestion of bronchial samples from lung transplants and were grown at the air-liquid interface, as described previously (6). Primary cultures were grown at the air-liquid interface for more than 2 weeks, by which time differentiation into a mucociliary epithelium occurs. DMSO, camptothecin, etoposide, aphidicolin, hydroxyurea, and genistein were purchased from Sigma Chemical Co. (St. Louis, Missouri, USA). Tripeptidyl aldehyde proteasome inhibitors $N$ acetyl-L-leucyl-L-leucyl-norleucine (LLnL; also called Calpain inhibitor I) and Carbobenzoxy-L-leucyl-Lleucyl-L-leucinal (Z-LLL; also called MG132) were purchased from Calbiochem-Novabiochem Corp. (La Jolla, California, USA). Ubiquitin ligase (E3) inhibitors were obtained from Bachem Bioscience Inc. (King of Prussia, Pennsylvania, USA). Anti-AAV capsid mAb (AntiVP1, 2, and 3) was purchased from American Research Products (Belmont, Massachusetts, USA) and antiubiquitin antibody was purchased from Santa Cruz Biotechnology Inc. (Santa Cruz, California, USA).
Production of recombinant $A A V$ viral stocks. Recombinant $A A V$ was produced by a $\mathrm{CaPO}_{4}$ cotransfection protocol and purified through three rounds of isopycnic cesium chloride ultracentrifugation as described previously (15). The proviral plasmid, pCisAV.GFP3ori, which encodes the EGFP reporter gene under transcriptional control by the CMV enhancer/promoter and SV40 polyadenylation signal, was used to generate AV.GFP3ori virus (16). The proviral plasmid, pCisRSV.Alkphos, which encodes the alkaline phosphatase reporter gene under the transcriptional control of the RSV promoter and SV40 polyadenylation signal, was used to generate AV.Alkphos (17). The proviral plasmid pCisRSV.LacZ used for AV.LacZ production was generated by first inserting a 3,474-bp Not I cut $\beta$-galactosidase gene (from pCMV $\beta$; Clontech Laboratories Inc., Palo Alto, California, USA) into the Not I site of the pRep4 (Invitrogen Corp./NOVEX, Carlsbad, California, USA). The entire $\beta$-galactosidase expression cassette, including the RSV promoter, $\beta$-galactosidase reporter gene, and SV40 polyA signal, was excised by Sal I digestion and subsequently cloned into the pSub201 backbone by blunt-end ligation (18). Recombinant viral stocks were heated at $58^{\circ} \mathrm{C}$ for 60 minutes to inactivate contaminating helper adenovirus. Typical yields were $5 \times$

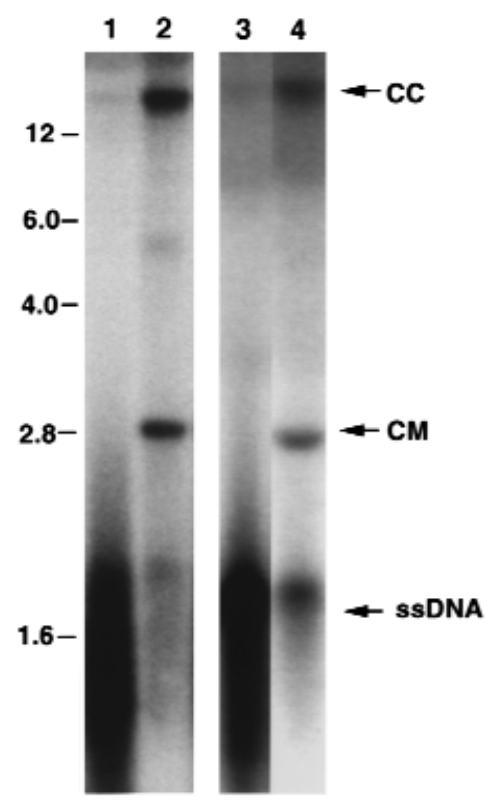

Figure 1

Southern blot analysis of AAV genomes in polarized airway epithelia. Differentiated human bronchial epithelial cultures were infected with AV.GFP3ori at an moi of 10,000 particles per cell from either the apical (lanes 1 and 3 ) or basolateral (lanes 2 and 4 ) surface. Fifty days after infection, Hirt DNA was harvested and electrophoresed in a $1 \%$ agarose gel. Each lane represents combined Hirt DNA from two transwell cultures, and the two gels are derived from two independent tissue samples. The Southern blot was hybridized to a $\left[\mathrm{P}^{32}\right]$-labeled EGFP probe and exposed to film for 48 hours. Molecular weight standards are marked to the left of the autoradiogram. The single-stranded and circular monomer forms of AAV viral DNA migrate at $1.6 \mathrm{~kb}$ and $2.8 \mathrm{~kb}$, respectively. ssDNA, single-stranded viral DNA; CM, circular monomer; CC, circular concatamer. 
$10^{8}$ to $5 \times 10^{9}$ particles per microliter based on DNA slot blot hybridization assays against plasmid standards. The levels of contamination with recombinant helper adenovirus and wild-type AAV-2 were less than 1 functional particle per $1 \times 10^{10} \mathrm{DNA}$ particles of $\mathrm{rAAV}$, as assessed by assays described previously (15). Purified virus was dialyzed in PBS before in vitro or in vivo infections.

Transduction of polarized airway epithelial cells and primary human fibroblasts. rAAV infection of fully differentiated bronchial cells was performed as described in a protocol published previously (6). For infections from the apical surface of the airway cells, $5 \mu \mathrm{L} \mathrm{rAAV}$ was mixed with $50 \mu \mathrm{L}$ of culture media and applied directly onto the apical compartment of Millicell inserts (Millipore Corp., Bedford, Massachusetts, USA) (moi $=10,000$ particles per cell). During apical infection, the basolateral side of the Millicell was continuously bathed in culture media. Gene transfer to the basal side was performed by inverting Millicell inserts and applying viral vector to the bottom of the supporting filter membrane in a $50-\mu \mathrm{L}$ volume for 2 hours. Subsequently, Millicell inserts were returned to the upright position, in the continued presence of the original viral inoculum plus an additional $450 \mu \mathrm{L}$ of media. For both apical and basolateral infections, rAAV-containing media was removed after 24 hours and replaced with either fresh culture media (for the basal side) or exposed to air (for the apical side). To test the effect of different chemicals on the efficiency of AAV transduction in polarized airway cells, $1 \mu \mathrm{L}$ of stock chemical solutions was mixed with AAV before infection of airway epithelia. Chemicals were usually presented during the 24-hour AAV infection period unless indicated otherwise. Most of the chemicals were dissolved in DMSO except for hydroxyurea (dissolved in PBS), H-Leu-Ala-OH (dissolved in $0.9 \%$ glacial acetic acid), and H-His-Ala-OH (dissolved in 50\% methanol). The working concentrations of the chemicals were as follows: $0.1 \mu \mathrm{M}$ camptothecin, $10 \mu \mathrm{M}$ etoposide, 5 $\mu \mathrm{g} / \mathrm{mL}$ aphidicolin, $40 \mathrm{mM}$ hydroxyurea, $50 \mu \mathrm{M}$ genistein, $40 \mu \mathrm{M} \mathrm{LLnL}$, and $4 \mu \mathrm{M} Z$-LLL. When the ubiquitin ligase (E3) inhibitors (H-Leu-Ala-OH and H-HisAla-OH) were used, airway cells were pretreated with a combination of both inhibitors at a final concentration of $2 \mathrm{mM}$ for 60 minutes before infection, followed by the continued presence of inhibitor $(0.2 \mathrm{mM})$ during the entire 24-hour infection period from the basolateral surface. Studies involving EGTA treatment were performed by transiently treating the apical membrane of polarized airway epithelia with $3 \mathrm{mM}$ EGTA in water for 10 minutes (6). After hypotonic EGTA treatment, cultures were washed twice with culture medium and infected with $\mathrm{rAAV}$ in the presence or absence of $40 \mu \mathrm{M} \mathrm{LLnL}$. Human primary fibroblast cells (P4) were maintained in $10 \%$ FBS, $1 \%$ penicillin and streptomycin, and 89\% DMEM. Infection with AV.GFP3ori was performed with $80 \%$ confluent fibroblasts at an moi of 1,000 DNA particles per cell in 2\% FBS DMEM for 24 hours.

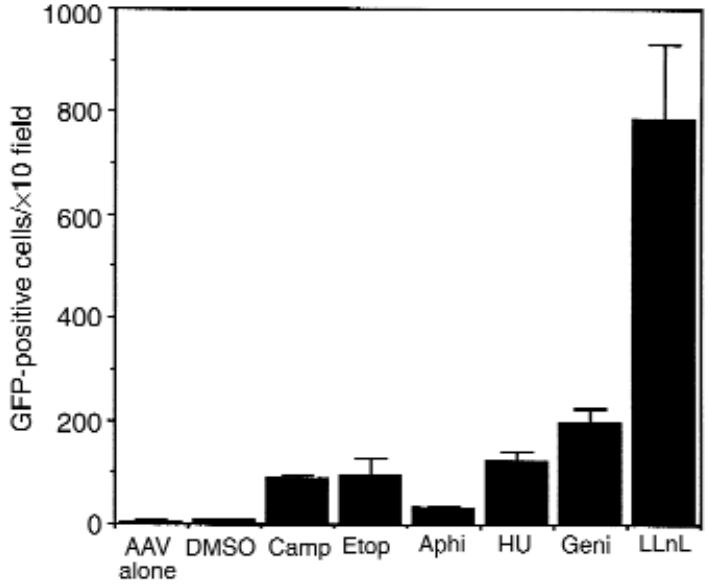

Figure 2

Effects of different chemical reagents on AAV transduction from the basolateral surface of polarized bronchial epithelia. Fully differentiated human bronchial airway epithelia were treated with the indicated chemicals at the time of AAV infection ( $\mathrm{moi}=10,000$ particles per cell) from the basolateral surface, as outlined in Methods. Camp: camptothecin at $0.1 \mu \mathrm{M}$; Etop: etoposide at $10 \mu \mathrm{M}$; Aphi: aphidicolin at $5 \mu \mathrm{g} / \mathrm{mL}$; HU: hydroxyurea at $40 \mathrm{mM}$; Geni: genistein at 50 $\mu \mathrm{M}$; and LLnL at $40 \mu \mathrm{M}$. Because most of the tested chemicals (except for hydroxyurea) were dissolved in DMSO, a vehicle control of $1 \%$ ( $\mathrm{vol} / \mathrm{vol})$ DMSO was also performed to exclude the possibility of a nonspecific effect. GFP expression was monitored at 48 hours after infection by counting the number of GFP-positive cells per $\times 10$ field in the Millicell. The data represent the mean \pm SEM of three independent infections for each tested chemical.

Viral binding/entry assays and in situ localization of viral particles. rAV.GFP3ori virions were metabolically labeled with $\left[\mathrm{S}^{35}\right]$ methionine according to a protocol published previously (19). Typical specific activities of labeled virus preparations were $5 \times 10^{-6}$ counts per minute (cpm) per particle. To assess the binding of rAAV to polarized bronchial epithelia cells, [ $\mathrm{S}^{35}$ ]-labeled AV.GFP3ori was applied to either the apical or basal surface ( $\mathrm{moi}=50,000$ particles per cell), followed by incubation at $4^{\circ} \mathrm{C}$ for 60 minutes. Combined binding/entry of rAAV into differentiated airway epithelia was measured under the same conditions, except that the cultures were incubated at $37^{\circ} \mathrm{C}$ for an additional $2-24$ hours before they were harvested. After washing three times in PBS, cells were lysed in situ by the addition of $5 \mathrm{~mL}$ of liquid scintillation cocktail at room temperature for 5 minutes, and the radioactivity was quantitated in a scintillation counter.

To analyze the subcellular localization of the rAAV particles within polarized human bronchial epithelial cells, infection was performed by applying $\left[\mathrm{S}^{35}\right]$-labeled virus ( $\mathrm{moi}=50,000$ particles per cell) to either the mucosal or serosal surface at $37^{\circ} \mathrm{C}$. At 2 hours after infection, transwells were washed with medium three times and fixed in $4 \%$ paraformaldehyde overnight before cryoprotection and embedding for frozen sectioning. Frozen sections $(10 \mu \mathrm{m})$ were overlaid with photoemulsion and developed for 5 weeks according to a protocol published previously (20). 
a

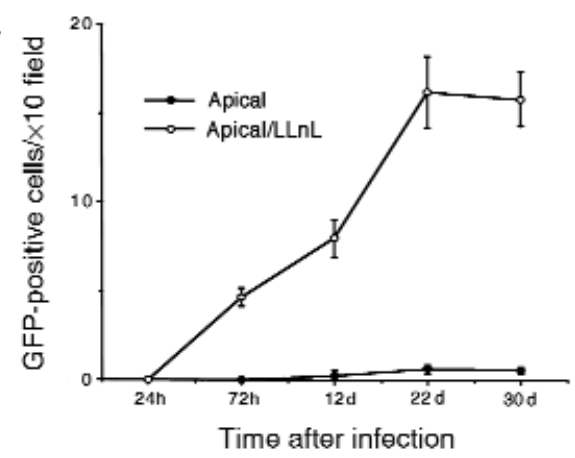

b

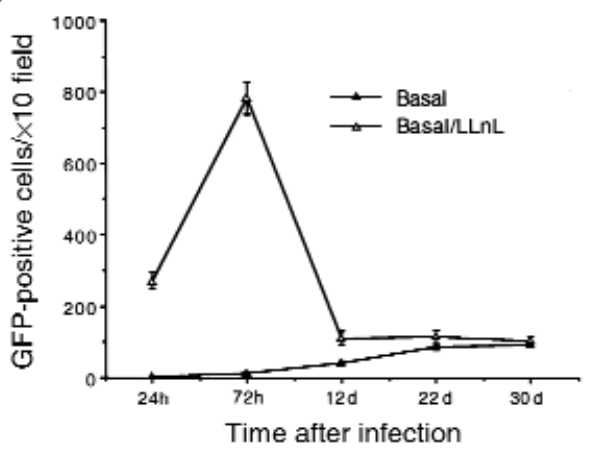

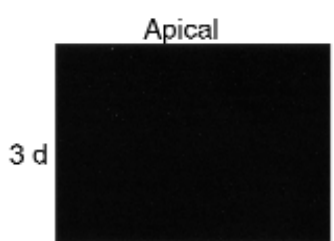
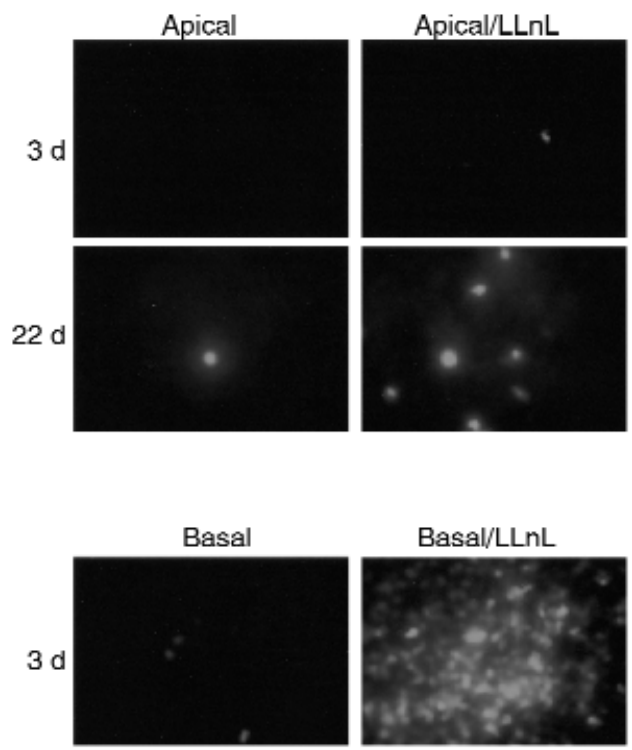

Basal/LLnL
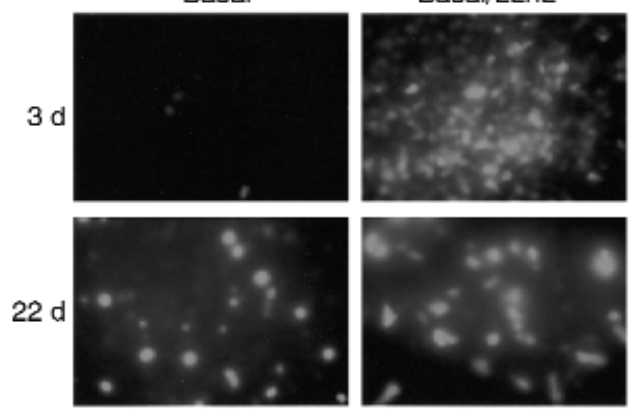

\section{Figure 3}

Proteasome inhibitors differentially augment rAAV transduction from the apical or basolateral surfaces of airway epithelia. The efficiency and time course of rAAV transduction were evaluated in polarized airway epithelial cultures after infection with rAV.GFPori3 ( $\mathrm{moi}=10,000$ particles per cell) in the presence or absence of $40 \mu \mathrm{M} \mathrm{LLnL}$. Transgene expression was monitored by indirect fluorescence microscopy at the indicated time points by quantifying the mean number of GFP-positive cells per $\times 10$ field (mean \pm SEM of three independent samples for each time point). The effect of LLnL treatment was compared between matched sets of tissue samples at each time point after infection from the apical (a) or basolateral (b) surfaces. The photomicrographs on the right side of each panel illustrate representative $\times 20$ fields for the 3- and 22-day time points after infection.

Molecular analysis of $r A A V$ viral genomes after infection of polarized airway epithelial cultures. The molecular state of bound and endocytosed virus was assayed at different times after rAAV infection. To examine the amount of virus attached to the cell surface, rAAV infection was performed at $4^{\circ} \mathrm{C}$ for 1 hour. After binding, the extent of viral internalization was assessed by continuing incubations in the presence of virus at $37^{\circ} \mathrm{C}$ for $4-24$ hours. Viral DNA was extracted according to a modified Hirt protocol and Southern blots performed with Hybond $\mathrm{N}+$ nylon membrane (Amersham Pharmacia Biotech Ltd., Little Chalfont, Buckinghamshire, United Kingdom) (15). The 1.6-kb single-stranded viral DNA, the $2.8-\mathrm{kb}$ double-stranded circular intermediate, and the 4.7-kb double-stranded replication form viral genome were detected with a transgene specific EGFP probe at $5 \times 10^{6} \mathrm{cpm} / \mathrm{mL}$. Blots were washed at a stringency of $0.2 \times \mathrm{SSC} / 0.1 \% \mathrm{SDS}$ at $55^{\circ} \mathrm{C}$ for 20 minutes twice. In studies aimed at evaluating viral internalization, virus attached to the cell surface was removed by trypsinization with $1 \mathrm{~mL}$ of buffer containing $0.5 \%$ trypsin, and $5.3 \mathrm{mM}$ EDTA at $37^{\circ} \mathrm{C}$ for 10 minutes $(500 \mu \mathrm{L}$ buffer was added to the apical and basolateral compartment of the Millicell inserts), followed by washing with icecold PBS twice. Externally bound AAV virus was deter- mined by the intensity of the $1.6-\mathrm{kb}$ viral genome band in Hirt DNA extracted from cells infected at $4{ }^{\circ} \mathrm{C}$ for 60 minutes followed by washing prior to harvesting of Hirt DNA. The internalized virus was determined by the intensity of the $1.6-\mathrm{kb}$ viral genome band in Hirt DNA extracted from trypsinized cells after infection at $37^{\circ} \mathrm{C}$ for 4 and 24 hours. The dynamic changes in the molecular structure of the internalized viral genomes were assayed at 2, 10, 30, and 50 days after virus was removed from culture medium.

Detection of ubiquitinated $A A V$ capsid proteins by immunoprecipitation. To analyze the effect of the proteasome inhibitor on AAV ubiquitination, human primary fibroblasts were lysed at 6 hours after viral infection in $1 \times$ RIPA buffer. Cell lysates were then cleared with $30 \mu \mathrm{L}$ Protein A-Agarose. The supernatant was incubated with $10 \mu \mathrm{L}$ of monoclonal anti-VP1, 2, and 3 antibody (Clone B1; American Research Products) followed by the addition of $30 \mu \mathrm{L}$ Protein A-Agarose. The pellets were washed four times with RIPA buffer and resolved on a $10 \%$ SDS-PAGE. After transfer to a nitrocellulose filter, blots were probed with a 1:1,000 dilution of antiubiquitin $\mathrm{mAb}$ (clone P4D1; catalog no. sc-8017; Santa Cruz Biotechnology), followed by 1:500 horseradish peroxidase-conjugated secondary 
antibody (BMB). After the final washings, immunoreactivity was visualized using the ECL system (Amersham Pharmacia Biotech Ltd.).

In vivo studies evaluating the effect of proteasome inhibitors on $A A V$-mediated gene transfer in lung, liver, and muscle. To determine the effect of the proteasome inhibitor on AAV-mediated gene transfer in mouse lung, 6-week-old $\mathrm{BALB} / \mathrm{c}$ mice were lightly anesthetized using a methoxyflurane chamber. AV.LacZ $\left(5 \times 10^{10}\right.$ particles $)$ was administered alone or with $400 \mu \mathrm{M} Z$ Z-LLL in a 10$\mu \mathrm{L}$ instillation by nasal aspiration as described previously (21). To prevent unforeseen toxicity of DMSO solvent, the proteasome inhibitor Z-LLL was dissolved in ethanol as a $40 \mathrm{mM}$ stock solution and was included in the viral inoculum at $1 \%$ final concentration. Viral infection controls in the absence of Z-LLL also contained a $1 \%$ final concentration of ethanol. Because studies in both primary cultured human airway cell and fibroblasts have demonstrated similar enhancement efficiency between $40 \mu \mathrm{M}$ LLnL and $4 \mu \mathrm{M} Z$ Z-LLL, and also due to the poor solubility of LLnL in ethanol, only Z-LLL was tested in mouse lung studies. The animals were euthanized at 3,10 , and 150 days after infection, and PBS $(10 \mathrm{~mL})$ was instilled into the right ventricle, followed by removal of the lungs and heart as an intact cassette. The trachea was intubated and instilled at $10 \mathrm{~cm}$ of pressure with the following solutions in order: PBS, $0.5 \%$ glutaraldehyde, $1 \mathrm{mM} \mathrm{MgCl} / 2 / \mathrm{PBS}$, and finally $\mathrm{X}$-gal staining reagent for an overnight incubation at room temperature. The X-gal-stained mouse lungs were then post-fixed in $10 \%$ neutral buffered formalin for 48 hours at room temperature and cryopreserved in serial $10 \%, 20 \%$, and $30 \%$ sucrose/PBS solutions. Lungs ( $n=3$ for each condition) were embedded in OCT (Baxter, Warrendale, Pennsylvania, USA), and $15 \mu \mathrm{m}$ sections were analyzed for gene transfer by calculating the percentage of positive cells in the airway epithelium. The diameter of the airway was recorded for classification (> $360 \mu \mathrm{m}, 260-350 \mu \mathrm{m}$, $160-250 \mu \mathrm{m}$, and $<150 \mu \mathrm{m}$ ) of results following morphometric analysis. Greater than 150 airway cross-sections were quantified for each experimental condition.

To examine the effect of proteasome inhibitors on AAV-mediated gene transfer in liver, 6-week-old C57BL/6 mice were anesthetized with ketamine /xylazine and a laparotomy was performed for direct portal vein injection of rAAV. LLnL and Z-LLL were dissolved in ethanol as a 20 or $40 \mathrm{mM}$ stock, respectively. AV.Alkphos $\left(5 \times 10^{10}\right.$ DNA particles) was instilled directly into the portal vein in a $200-\mu \mathrm{L}$ volume over a period of 30 seconds, either alone or in the presence of $200 \mu \mathrm{M}$ LLnL or $40 \mu \mathrm{M} Z$ Z-LLL. To control for any nonspecific effect of the solvent, AV.Alkphos infection alone was also carried out in $1 \%$ ethanol solution. Mouse livers were harvested at 2 and 4 weeks after infection, and each liver lobe was immediately embedded individually in OCT. Alkaline phosphatase transgene expression was evaluated by histochemical staining in $15-\mu \mathrm{m}$ frozen sections as described previously (20). For each lobe of the liver, approximately 40 sections were analyzed to determine the percentage of alkphos-positive (AP-positive) cells. The gene transfer efficiency in each animal was calculated by averaging the percentage of AP-positive cells from all six lobes of the liver.

To test whether proteasome inhibitors would also enhance rAAV-2-mediated gene transfer in muscle, rat cardiac muscle and mouse skeletal muscle were infected with rAAV in the presence or absence of proteasome inhibitors. Cardiac muscle infection was performed in 200- to 250-g male Wistar rats. In animals anesthetized with ketamine/xylazine, tracheas were cannulated and artificial respiration was initiated using a Harvard rodent respirator under the condition of a $6-\mathrm{mL}$ tidal volume and a rate of 60 strokes per minute. After a left thoracotomy, $25 \mu \mathrm{L}$ of AV.GFP3ori ( $2 \times 10^{10}$ particles $)$, with or without $200 \mu \mathrm{M}$ LLnL or $40 \mu \mathrm{M}$ Z-LLL, was
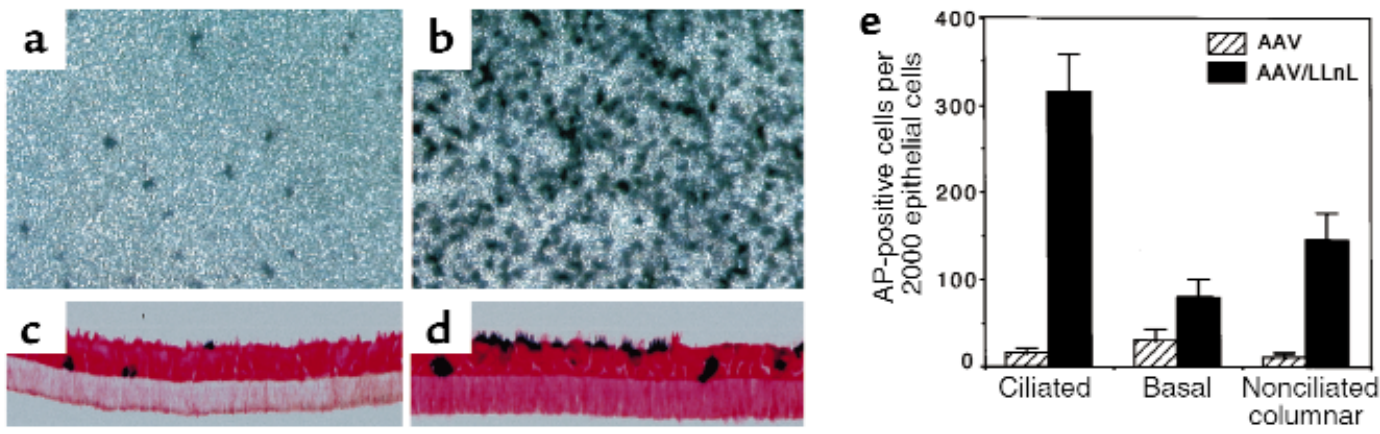

\section{Figure 4}

The proteasome inhibitor LLnL preferentially induces AAV transduction in ciliated cells. The cell types transduced by AAV were examined by alkaline phosphatase staining at 3 days after basolateral infection of polarized epithelial cultures with AV.Alkphos infection (moi $=10,000$ particles per cell) in the presence or absence of $40 \mu \mathrm{M} L L n L$. En face photomicrographs in a (without LLnL) and $\mathbf{b}$ (with LLnL) depict enhanced rAAV transduction in the presence of LLnL. Paraffin sections $(8 \mu \mathrm{m})$ were used to histologically quantify the types of cells transduced. Three classifications were used: ciliated cells (with alkphos expression localized to the apical membrane and cilia), basal cells residing in the lower half of the epithelium with no contact with the lumen, and nonciliated columnar cells. c (without LLnL) and $\mathbf{d}$ (with LLnL) show representative neutral red counterstained cross-sections for each condition. The numbers of alkphos-stained cells per 2,000 epithelial cells for the various cell types transduced by AAV are presented in e (mean \pm SEM from three independent Millicell insert samples). 

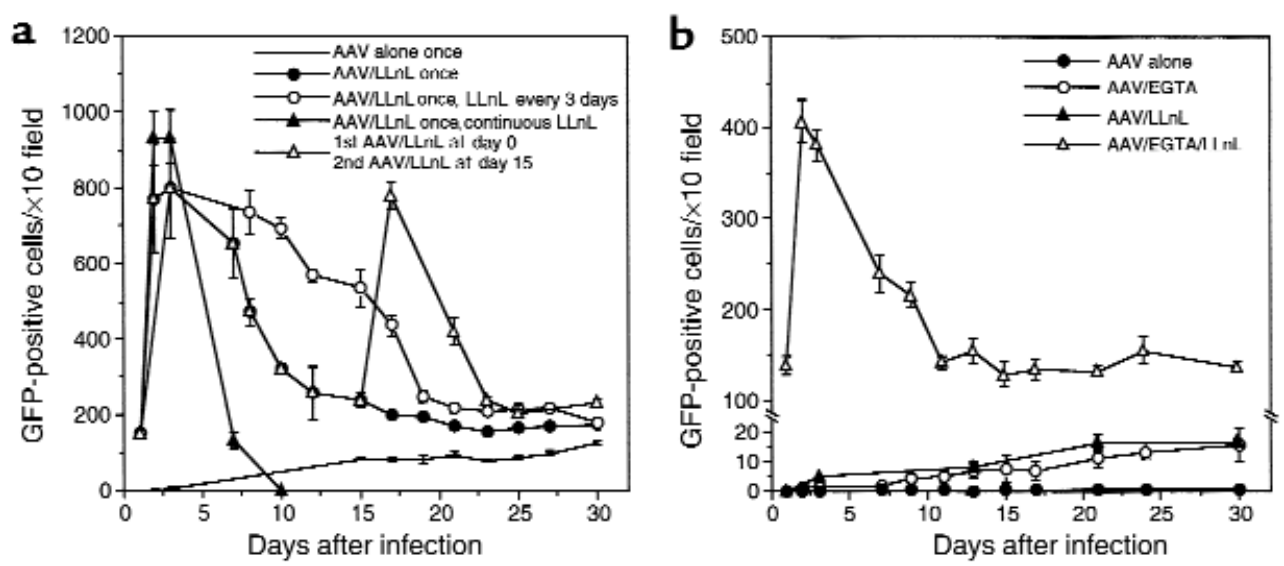

\section{Figure 5}

Optimization of LLnL-enhanced rAAV transduction in polarized bronchial epithelia. Differentiated airway epithelia were infected with AV.GFP3ori (10,000 particles per cell) from either the basolateral (a) or the apical (b) surface with the indicated treatments involving LLnL and/or EGTA. All infections were carried out for 24 hours, and GFP transgene expression was monitored by indirect fluorescent microscopy at the indicated times. Data represent the mean $( \pm \mathrm{SEM} ; n=6)$ for each experimental condition. Experiments were performed in triplicate on transwells derived from samples obtained from two different patients. The following conditions were evaluated for basolateral infection in a: single infection with AV.GFP3ori alone (solid line); single infection with AV.GFP3ori in the presence of $40 \mu \mathrm{M} \mathrm{LLnL} \mathrm{(filled} \mathrm{circles);} \mathrm{single} \mathrm{infection} \mathrm{with} \mathrm{AV.GFP3ori}$ in the presence of $40 \mu \mathrm{M} \mathrm{LLnL}$ followed by repeated 5-hour exposure to $40 \mu \mathrm{M}$ LLnL in the basal compartment culture medium every third day thereafter (open circles); single infection with AV.GFP3ori in the presence of $40 \mu \mathrm{M} \mathrm{LLnL}$ followed by the continued exposure to $40 \mu \mathrm{M} L L n L$ in the basal medium after rAAV was removed (filled triangles); and repeated infection with AV.GFP3ori on days 0 and 15 in the presence of $40 \mu \mathrm{M}$ LLnL for 24 hours at the time of infection (open triangles). The following conditions were evaluated for apical infection in b: single infection with AV.GFP3ori alone (filled circles); single infection with AV.GFP3ori after pretreatment with $3 \mathrm{mM}$ hypotonic EGTA before the viral infection (open circles); single infection with AV.GFP3ori in the presence of $40 \mu \mathrm{M} \mathrm{LLnL}$ (filled triangles); and single infection with AV.GFP3ori in the presence of $40 \mu \mathrm{M} \mathrm{LLnL}$ after pretreatment with $3 \mathrm{mM}$ hypotonic EGTA before the viral infection (open triangles).

injected directly into the left ventricular wall through a Hamilton syringe with a 33-gauge needle. GFP expression was monitored either by direct immunofluorescence of freshly excised tissues, or in $4 \%$ formaldehydefixed, cryopreserved tissue sections from hearts harvested at 1, 3, and 6 weeks after infection. The effect of proteasome inhibitors on skeletal muscle transduction was evaluated on the tibialis anterior muscle of 4- to 5 -week-old C57BL/6 mice. A total of $30 \mu \mathrm{L}$ of AV.Alkphos $\left(3 \times 10^{10}\right.$ particles $)$ was injected according to a protocol published previously (16), in the presence or absence of $200 \mu \mathrm{M}$ LLnL or $40 \mu \mathrm{M}$ Z-LLL. Alkaline phosphatase expression was evaluated on $10-\mu \mathrm{m}$ cryosections of muscle samples harvested at 1 week and at 1 and 3 months after infection. Histochemical staining for heatresistant alkaline phosphatase was performed at $37^{\circ} \mathrm{C}$ for 10 minutes, and sections were coverslipped with Aquamount (Lerner Laboratories, Pittsburgh, Pennsylvania, USA). The percentage of myofibers that were APpositive was evaluated for each muscle section. In total, at least 20 sections were quantified for each individual muscle sample, and the entire cross-sectional area of the muscle section was evaluated for gene transfer.

\section{Results}

Molecular analysis of $r A A V$ genomes in polarized airway epithelia. Recent studies have revealed a lack of AAV-2 receptor (heparan sulfate proteoglycan) and coreceptors (FGFR- 1 and $\alpha \mathrm{V} \beta 5$ integrin) at the apical surface of differentiated airway epithelia $(6,7,22)$. However, differences in the binding of radioactive rAAV-2 virus at the apical and basolateral membranes were only four- to sevenfold (basolateral > apical). These differences in binding are insufficient to explain the 200-fold variance observed in the polarity of infection (basolateral > a pical) with rAAV-2 (6). These findings suggested that viral binding and/or uptake were not the sole limiting factors contributing to inefficient mucosal transduction in airway epithelia. We hypothesized that additional barriers, such as endosomal processing and/or the molecular conversion of viral genomes, might also contribute to the inefficient infection from the apical surface of airway epithelia. To this end, we evaluated the molecular state of rAAV DNA at 50 days after apical and basolateral infection of air-liquid interface-cultured human bronchial epithelia. At this time point, gene expression measured from an EGFP reporter was more than 200 -fold higher in basolaterally infected cultures (data not shown) (6). Hirt DNA from the cultures was evaluated by Southern blot hybridization with $\left.{ }^{32} \mathrm{P}\right]$-labeled EGFP probes. As shown in Figure 1, a significant amount of apically applied rAAV was able to infect airway cells. However, only single-stranded viral genomes (ssDNA) were detected at this time point (50 days). This result clearly suggests that rAAV can be endocytosed from the mucosal surface and that the endocytosed viral ssDNA was stably sequestered in some unknown subcellular 
compartment. In contrast, the majority of basolaterally applied rAAV was converted into double-stranded forms that migrated at $2.8 \mathrm{~kb}$ and greater than $12 \mathrm{~kb}$ in $1 \%$ nondenaturing agarose gels (Figure 1 ). Consistent with our previous reports $(13,23)$, subsequent restriction enzyme mapping with Hirt DNA Southern blots confirmed this $2.8-\mathrm{kb}$ band to be a supercoiled, circular episomal molecule (data not shown). The identity of the greater than $12-\mathrm{kb}$ band, which is significantly more intense after basolateral infection, is currently unknown but may represent episomal circular concatamers of the AAV genome. Taken together, our results suggest that inefficient molecular conversion of AAV viral DNA to circular genomes represents a significant obstacle for rAAV-mediated gene transfer from the apical surface of the airway. Furthermore, circularization, not linear replication through self-priming, appears to be the predominant pathway for rAAV gene conversion in polarized airway epithelia.

Proteasome inhibitors dramatically enhance $r A A V$ infection in polarized airway epithelia. Given that rAAV appears to remain latent within some cellular compartment(s) after apical infection in the airway, we sought to investigate whether agents that alter the molecular conversion of the viral genome might enhance rAAV transduction in airway epithelia. Several chemicals, including DNA-damaging agents (24), DNA synthesis and topoisomerase inhibitors (25), and cellular tyrosine kinases inhibitors $(26,27)$, have been shown to increase the AAV transduction efficiency in cultured primary fibroblasts and/or transformed cell lines. Application of camptothecin, etoposide, hydroxyurea, and genistein resulted a ten-to 60 -fold enhancement in rAAV transduction from the basolateral surface (Figure 2). Interestingly, however, none of these reagents facilitated rAAV transduction from the apical surface (data not shown).

Because chemicals known to affect intranuclear events involved in rAAV transduction in other cell types (28) did not enhance $\mathrm{rAAV}$ apical infection in the airway, we sought instead to assess chemicals that might affect endocytic processing of internalized virions. Proteasome systems are known to modulate the intracellular processing of many foreign and endogenous molecules, including viruses such as HIV (29). Several specific, cellpermeable, peptide aldehyde inhibitors of proteasome pathways have recently been discovered $(30,31)$. These inhibitors bind to the active sites of proteolytic enzymes within the proteasome core and reversibly block their function (32). To test whether proteasomes represent an intracellular compartment that sequesters rAAV after infection, we applied the tripeptidyl aldehyde proteasome inhibitor (a cysteine protease inhibitor) LLnL to polarized cultures of human bronchial epithelial cells at the time of rAAV infection. To our surprise, a greater than 200-fold augmentation in transgene expression was obtained at 2 days after infection when $40 \mu \mathrm{M}$ LLnL was applied to the serosal surface along with rAAV (Figure 2). A similar result was achieved when another ubiquitinproteasome pathway inhibitor, Z-LLL (33), was tested (data not shown). However, as described later here, the most important finding was that these proteasome inhibitors also substantially increased rAAV transduction from the mucosal surface. When compared with other chemicals tested, proteasome inhibitors were found to be the most potent enhancers of rAAV transduction in airway epithelium.

Proteasome inhibitors angment $\mathrm{AAV}$ transduction in airway epithelia in a polarized fashion. To test the effect of proteasome inhibitors on rAAV transduction from the apical membrane, we performed a side-by-side kinetic comparison of rAAV transduction from both mucosal and serosal surfaces of airway epithelia after treatment with LLnL. As shown in Figure 3a, coadministration of LLnL and rAAV to the mucosal surface resulted a sustained augmentation in AAV transduction, which peaked at 22 days after infection. In contrast to mucosal infection,

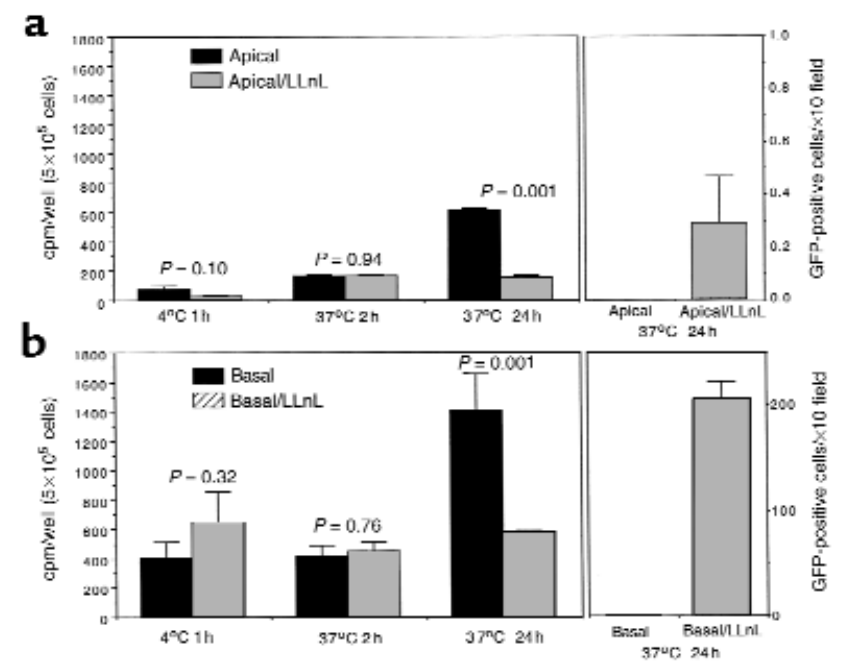

\section{Figure 6}

Binding and uptake of $\left[\mathrm{S}^{35}\right]$-labeled AV.GFP3ori in fully differentiated human bronchial epithelia. The ability of polarized bronchial epithelia to bind and internalize virus from the apical (a) and the basolateral (b) surfaces was quantified using $\left[\mathrm{S}^{35}\right]$-labeled rAAV. The binding assay was performed after incubation with virus at $4^{\circ} \mathrm{C}$ for 1 hour, followed by repeated washing in PBS. The combined bound and internalized virus was quantified after incubation with virus at $4^{\circ} \mathrm{C}$ for 1 hour, and subsequent incubation at $37^{\circ} \mathrm{C}$ for 2 hours or 24 hours. Nonspecific background binding of radiolabeled virus was determined in parallel studies on collagen-coated empty chambers not seeded with bronchial cells. Background counts (averaging 15.67 $\pm 5.17 \mathrm{cpm} /$ well) were subtracted from experimental sample counts before analysis. Data in the left side of each panel are presented as the net cpm of bound/internalized virus (raw counts minus background counts of empty transwells). The results represent the mean $( \pm$ SEM) of six independent transwells for each condition. Experiments were performed in triplicate from two independent tissue samples. The significance of the differences between each pair of samples (with or without LLnL) was evaluated using the Student's $t$ test, and $P$ values are provided above the data for each condition. To correlate uptake of radioactive virus with the functional expression of the rAAV-encoded transgene, GFP expression from the same set of samples was quantified at 24 hours after infection by indirect fluorescent microscopy. The results (mean $\pm \mathrm{SEM} ; n=6$ ) are presented as a bar graph on the right side of each panel. 

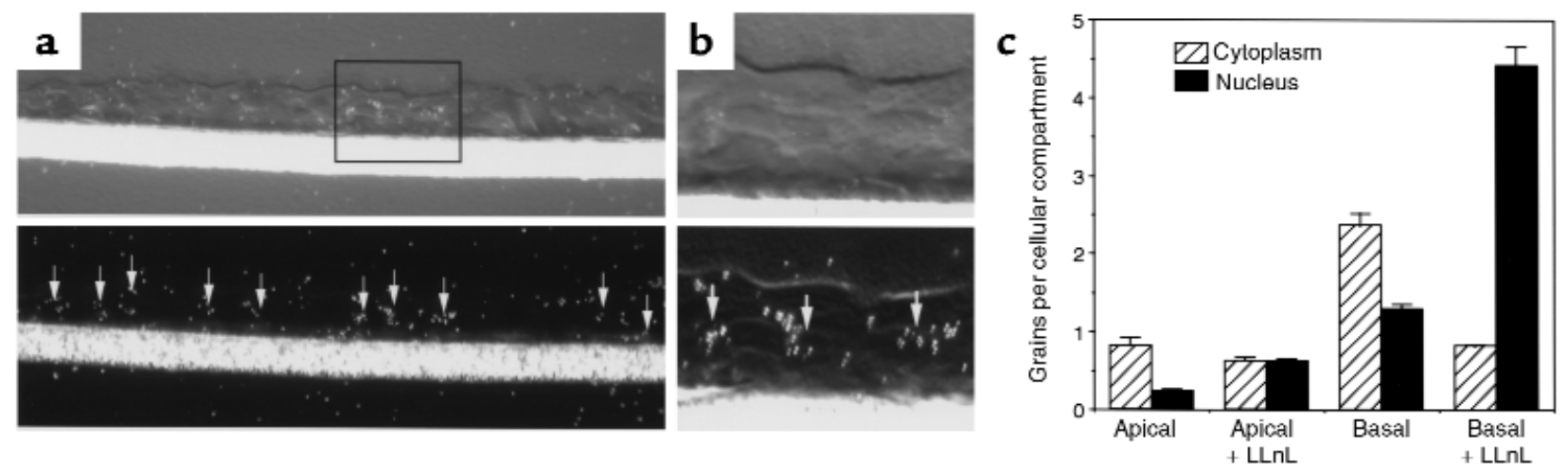

\section{Figure 7}

In situ localization of rAAV in the polarized airway epithelia using $\left[\mathrm{S}^{35}\right]$-labeled virus. Polarized human airway epithelia were infected with $\left[\mathrm{S}^{35}\right]$-labeled virus ( $\mathrm{moi}=50,000$ particles per cell) from either the apical or basolateral side ( $\pm \mathrm{LLnL}$ ). At 2 hours after infection, Millicells were washed with media three times and fixed in $4 \%$ paraformaldehyde overnight before cryoprotection in sucrose and OCT embedding. Frozen sections $(10 \mu \mathrm{m})$ were overlaid with photoemulsion and developed after 5 weeks of exposure. (a) The typical localization pattern after basolateral infection in the presence of LLnL. Arrows indicate nuclear-associated virus. (b) Enlargements of boxed regions in a. Blinded morphometric quantification was performed by counting the number of nuclear-associated and cytoplasmic radioactive grains of 10 random fields, as shown in a. A total of 60 cells was quantitated per field, to give a total of 600 cells per sample and 2,400 cells per condition. Results in $\mathbf{c}$ are the mean \pm SEM of four independent samples for each condition.

rAAV infection from the serosal surface in the presence of LLnL resulted only in a transient peak in gene expression at 72 hours after infection, which returned to the levels equivalent to those of the untreated samples by 22 days (Figure $3 \mathrm{~b}$ ). These results suggested that the proteasome inhibitor LLnL produces different augmentation profiles when $A A V$ virus is applied to either the apical or the basolateral membranes. To exclude potential effects caused by polarized uptake of LLnL by airway epithelia, we tested different combinations of rAAV and LLnL administration from both apical and basolateral surfaces. Similar augmentation patterns for AAV transduction were achieved, regardless of whether LLnL was applied to the same or opposite surface as rAAV during infections (data not shown).

To expand these findings, we examined whether LLnL administration augmented rAAV transduction of particular airway cell types. We utilized a rAAV vector encoding the alkaline phosphatase gene (Alkphos) and evaluated transduced cell types by standard histochemical staining for Alkphos to address this question. In the absence of LLnL, rAAV preferentially transduced basal cells at 3 days after serosal application of virus (Figure 4, a and c). Consistent with previous findings utilizing AV.GFP3ori virus, coadministration of LLnL resulted a dramatic increase in AV.Alkphos transduction (Figure 4, b and d). Interestingly, ciliated cell transduction was most significantly increased by treatment with LLnL at the time of rAAV infection (Figure 4e). In contrast, basal cells were the least responsive to $L L n L$ treatment. These findings indicated that the mechanisms of LLnL action may have some cellspecific components, which differ in polarized (i.e., ciliated) and nonpolarized (i.e., basal) cell types.

Optimization of LLnL enhanced $r A A V$ transduction. With the aim of further improving the enhancement in rAAV transduction achieved in the presence of LLnL, we performed several detailed kinetic studies altering the timing and number of LLnL administrations after rAAV infection (Figure 5). Several important conclusions arose from these studies. First, after basolateral infection (Figure 5a), administration of LLnL once every 3 days increased the length of peak transgene expression, despite the fact that by the end of 30 days, levels were similar to those of cultures treated once at the time of infection. Second, continual administration of LLnL was toxic to cells and ablated transgene expression by 10 days. Third, reinfection of cultures with $\mathrm{rAAV}$ in the presence of $\operatorname{LLnL}$ at 7, 10, and 15 days resulted in a similar pattern of augmentation and, as expected, elevated the final level of transgene expression observed at 30 days (only data from the second infection at 15 days are shown). Most notably, however, all the cultures infected from the basolateral side in Figure 5a produced similar long-term transgene expression levels within two- or threefold of each other, regardless of whether LLnL was administered.

Despite the fact that LLnL administration at the time of the viral infection augmented rAAV transduction from both the apical and basolateral surfaces, the kinetics of this induction were significantly different. Enhancement after basolateral infection was transient, whereas enhancement after apical infection was long term (Figure 3). Furthermore, although induction with LLnL from the apical membrane was longlasting, by 30 days the maximal level of transgene expression was only one eighth of that resulting from basal infection (Figure 3a). The application of hypotonic EGTA solution has been shown to increase AAV transduction from the apical surface by seven- to tenfold $(6,21)$. Therefore, we tested whether the combined administration of EGTA and LLnL could provide yet a further increase in rAAV transduction from 
the apical surface. Interestingly, treatment of airway cultures with EGTA before infection with $\mathrm{rAAV}$ in the presence of LLnL gave a transient peak in transduction within the first 3 days, and, a significantly increased (200-fold), prolonged level of transgene expression out to 30 days (Figure $5 \mathrm{~b}$ ). This prolonged level of transgene expression, while comparable to rAAV infection from the basal surface, was much above the level observed in apically infected epithelia treated with EGTA alone (Figure 5b). In summary, these results demonstrate that EGTA and LLnL have synergistic effects on rAAV transduction, allowing transduction from the apical surface at levels normally only seen after basolateral infection.

Viral binding and internalization are not affected by $L L n L$ treatment. The action of LLnL has been typically attributed to its selective and reversible inhibition of the proteasome system. However, it was important to rule out any possible effect on viral binding and/or endocytosis. As has been found for type 1 herpes simplex virus (34), LLnL treatment had no significant effect on $4^{\circ} \mathrm{C}$ rAAV binding (Figure 6). Similarly, the uptake of $\left[\mathrm{S}^{35}\right]$ labeled rAAV for a 2 -hour infection period at $37^{\circ} \mathrm{C}$ was not altered by LLnL treatment (Figure 6). Given these results, we conclude that LLnL acts at points distal to virus binding and entry. Interestingly, at 24 hours after infection, a very significant decrease in the amount of intracellular radioactivity was observed in epithelia treated with LLnL, regardless of which surface was infected (Figure 6). Given the concordant increase in transgene expression at this time point (Figure 6), we reasoned that LLnL may be accelerating processing and routing of the virus to the nucleus, where uncoating and clearance of $\left[\mathrm{S}^{35}\right]$-labeled capsid proteins occur. By this mechanism, $S^{35}$ isotope would be diluted into the culture medium and could explain the decrease in cell-associated counts.

LLnL enhances endosomal processing and nuclear trafficking of $r A A V$. To test the hypothesis that LLnL increases trafficking of rAAV to the nucleus, we performed in situ localization of the $\left[\mathrm{S}^{35}\right]$-labeled rAAV particles after infection from the apical and basolateral surfaces in the presence and absence of LLnL. Because loss of intact radiolabeled capsid proteins occurred at 24 hours after infection, we chose a 2 -hour time point for this analysis. Using photoemulsion overlay, we evaluated the subcellular distribution of $\left[\mathrm{S}^{35}\right]$-labeled $\mathrm{rAAV}$ particles by blinded morphometric analysis. As shown in Figure 7, the majority of viral particles localized to the cytoplasm in the absence of LLnL. This was the case regardless of whether infection was performed from the apical or basolateral surface. In contrast, LLnL treatment substantially changed the intracellular distribution of radiolabeled rAAV particles, resulting in a significant shift to nuclear associated grains. These results substantiated the findings from whole cell counts at 24 hours after infection, which suggested that LLnL increases viral uncoating and the subsequent loss of $\mathrm{S}^{35}$ isotope into the media.
LLnL augments $r A A V$ transduction within a specific time frame after infection. Evidence thus far has suggested that LLnL may act to increase intracellular routing of rAAV to the nucleus. Additionally, LLnL action is independent of the epithelial surface to which it is administered (i.e., serosal application of LLnL augments mucosal infection and visa versa). This indicates that LLnL need not be endocytosed with AAV particles to enhance transduction. We therefore hypothesized that LLnL may act at a specific time after $\mathrm{rAAV}$ endocytosis but during endosomal processing. To provide functional support for this hypothesis, we performed a kinetic analysis of LLnL action at various times after infection from the basolateral surface. In these experiments, LLnL was added to the culture medium either at the time of AAV infection or at various time points after infection. Viralmediated transgene expression was quantified at 24hour intervals after infection. Augmentation was achieved regardless of whether LLnL was administrated at $0,24,48$, or 72 hours after viral infection. However, addition of LLnL at 24 or 48 hours gave the strongest

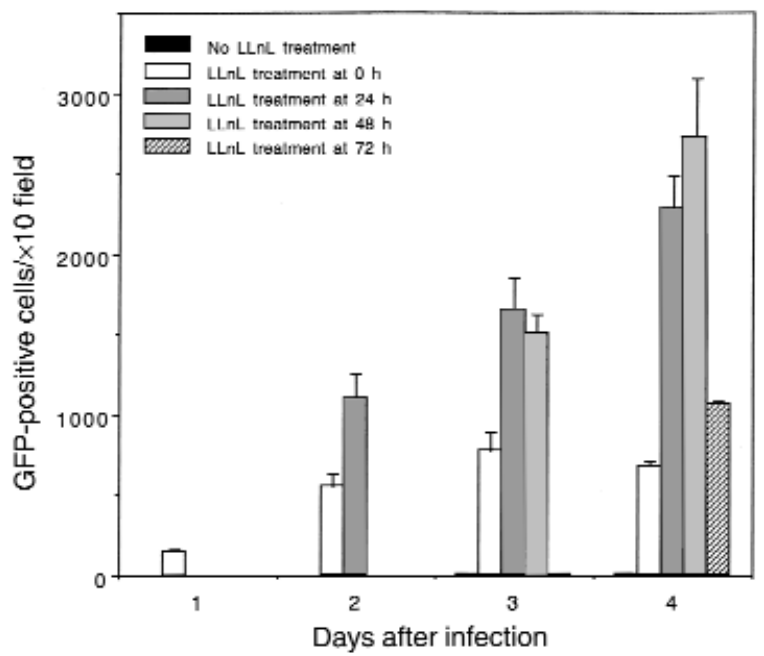

\section{Figure 8}

LLnL induces rAAV transduction within a specific time frame after infection. To study the kinetic effects of LLnL administration on AAV transduction, the proteasome inhibitor LLnL was added to the culture medium at different times after $\mathrm{rAAV}$ infection from the basolateral surface of airway epithelia. All cultures were infected with AV.GFP3ori $(10,000$ particles per cell $)$ at 0 hours. LLnL $(40 \mu \mathrm{M})$ was added at the time of infection ( 0 hours) or at 24-hour intervals after infection (24, 48 , or 72 hours). The baseline of AAV transduction in the absence of LLnL treatment is also shown. GFP expression was quantified at 1, 2, 3 , and 4 days after infection using indirect fluorescent microscopy and is presented as GFP-positive cells per $\times 10$ field. The data in each panel represent the mean $( \pm$ SEM) from three independent samples. The immediate increase in rAAV-mediated transgene expression after addition of LLnL is consistent with the hypothesis that LLnL acts by enhancing endosomal processing of viral particles from the cytoplasm to nucleus where it can be expressed. Furthermore, the addition of LLnL at 2-3 days after infection gave rise to higher levels of transgene gene expression than application of LLnL at the time of infection. These results support the notion that viral binding and internalization are not likely the steps enhanced by LLnL. 

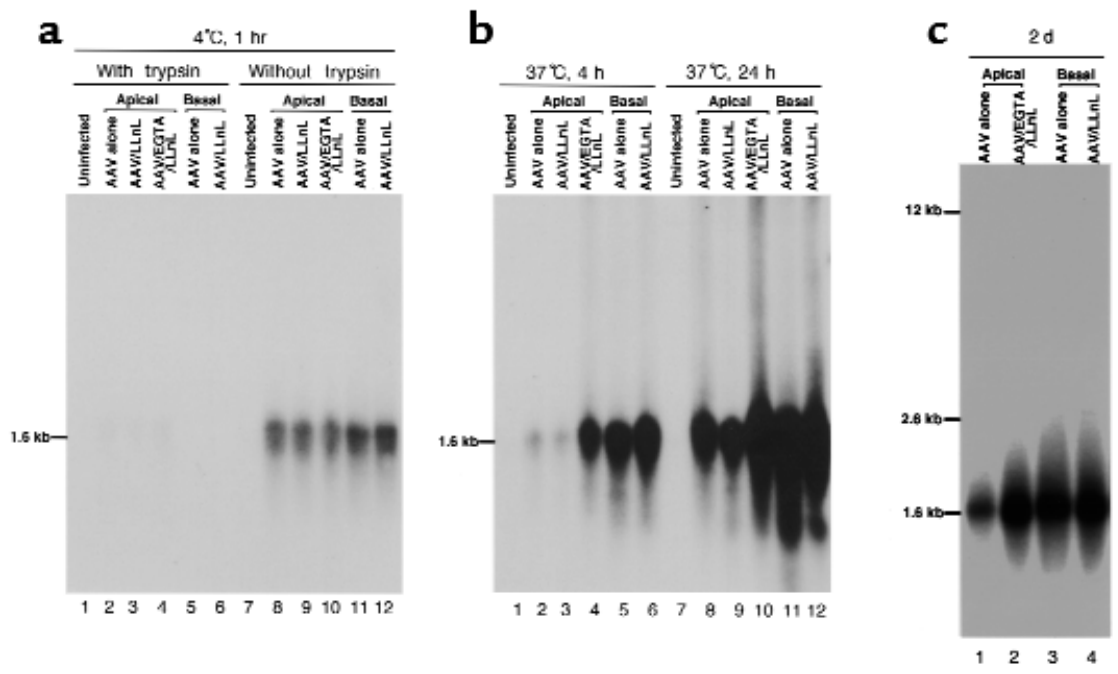

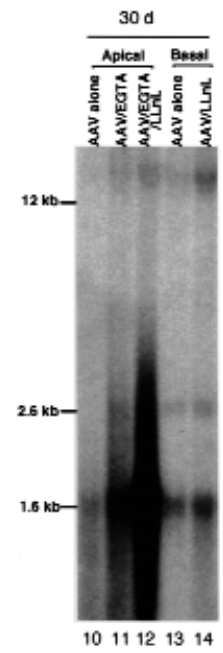

Figure 9

Examination of rAAV endocytosis by Southern blot analysis of viral DNA. Hirt DNA from AV.GFP3ori-infected or mock-infected (lanes 1 and 7 in both $\mathbf{a}$ and $\mathbf{b}$ ) human bronchial epithelia were extracted for a direct examination of viral genomes by Southern blotting against a [ $\left.\mathrm{P}^{32}\right]$ labeled EGFP probe. (a) Viral binding studies in the presence and absence of LLnL with or without EGTA treatment before apical or basolateral infection for 1 hour at $4^{\circ} \mathrm{C}$. Cell surface-bound virus was completely removed by trypsin (a, lanes 2 through 6 ). To determine the amount of the surface-bound rAAV, cells were infected with AV.GFP3ori for 1 hour at $4^{\circ} \mathrm{C}$ and were not treated with trypsin but rather washed before Hirt DNA extraction. a: Lanes 2 and 8: apical AAV infection; lanes 3 and 9: apical AAV infection in the presence of LLnL; lanes 4 and 10: cells were pretreated with hypotonic EGTA before apical infection in the presence of LLnL; lanes 5 and 11: basolateral infection; lanes 6 and 12: basolateral infection in the presence of LLnL. (b) Results of studies evaluating rAAV internalization from either the apical or the basolateral surface in the presence or absence of LLnL, and the internalization from the apical surface after combined treatment with hypotonic EGTA and LLnL. To detect the net amount of the internalized viral genome, all samples in $\mathbf{b}$ were treated with trypsin just before Hirt DNA was harvested. The extent of the internalized virus at 4 hours (b, lanes 2 through 6 ) and 24 hours (b, lanes 8 through 12) incubation at $37^{\circ} \mathrm{C}$ after infection is represented by the intensity of the $1.6-\mathrm{kb}$ single-stranded viral genome band. b: Lane 2: apical AAV infection for 4 hours; lane 3: apical AAV infection in the presence of LLnL for 4 hours; lane 4: cells were pretreated with hypotonic EGTA before apical infection in the presence of LLnL for 4 hours; lane 5: basolateral infection for 4 hours; lane 6: basolateral infection in the presence of LLnL for 4 hours; lane 8: apical infection for 24 hours; lane 9: apical infection in the presence of LLnL for 24 hours; lane 10: cells were pretreated with hypotonic EGTA before apical infection in the presence of LLnL for 24 hours; lane 11: basolateral infection for 24 hours; lane 12: basolateral infection in the presence of LLnL for 24 hours. (c) Comparison of the effect of LLnL/EGTA on rAAV genomes at 2, 10, and 30 days after a 24-hour infection from the apical (lanes 1, 2, 5, 6, 10, 11, and 12) and basolateral (lanes 3, 4, 7, 8, 9, 13, and 14) membranes. Treatment conditions are noted above each lane; transwells were not treated with trypsin before harvesting Hirt DNA. An additional control included coinfection with Ad.dl802 ( $\mathrm{moi}=500$ particles per cell) to demonstrate replication form monomers (lane 9, $4.7 \mathrm{~kb}$ ). It should be noted that different exposure times were used for the three different panels in $\mathbf{c}$ (lanes 1-4, 3 hours; lanes 5-8, 15 hours; and lanes 10-14, 12 hours). Matched DNA samples from uninfected cultures did not demonstrate detectable hybridization (data not shown).

level of augmentation. The ability of LLnL to rescue AAV expression appeared to decline by 72 hours after infection (Figure 8) and was completely lost by 15 days after the initial AAV infection (data not shown). Taken together, we hypothesize that after rAAV enters the cell, it may be targeted to an intracellular compartment that is sensitive to proteasome inhibitor-facilitated liberation. In addition, the loss of an LLnL augmentation effect at 15 days after infection suggests that enhanced transcription, translation, and/or stability of the transgene products do not likely contribute to the mechanism responsible for our observation.

Combined treatment of LLnL and EGTA prevents degradation of internalized $r A A V$. To clarify further the molecular mechanism(s) responsible for augmentation of rAAV transduction by LLnL, we analyzed rAAV genomes in infected cells by Southern blotting Hirt DNA. Consistent with studies using $\left[\mathrm{S}^{35}\right]$-labeled virus (Figure 6), rAAV binding to either surface of polarized airway epithelia was not affected by LLnL treatment (Figure 9a, lanes 8 and 9 for apical infection, lanes 11 and 12 for basal infection). Southern blotting also demonstrated two- to sevenfold higher viral binding from the basal surface, which varied among different tissue samples (data not shown). The extent of virus internalization was compared after stripping surface-bound virus with trypsin. Confirming previous results (Figures 1, 6, and 7), a significant amount of rAAV was endocytosed from the apical surface during the infection period (Figure 9b, lanes $2,3,8$, and 9), although viral uptake was more active from basolateral surface (Figure 9b, lanes 5, 6, 11, and 12). LLnL alone also did not substantially prevent enzymatic degradation of the internalized AAV viral DNA (Figure 9b; also see Figure 6), indicating that enhanced viral trafficking into the nucleus might be more important in the observed augmentation by LLnL. However, treatment with both hypotonic EGTA and LLnL substantially increased the amount of virus internalized 
from the apical surface (Figure 9b, compare lanes 2, 4 and lanes 8, 10; Figure 9c, compare lanes 1, 2, and 5, 6, and 10,12$)$. Given that hypotonic EGTA treatment alone only slightly increased persistence of AAV DNA (less than fourfold; Figure 9c, lane 11) or AAV-mediated gene expression (less than tenfold; Figure $5 b)(6,21)$ after apical infection, we reasoned that the predominant mechanism responsible for the combined effects of EGTA and LLnL might be due to reduced degradation of the internalized virus and an increased rate of endocytosis. These synergistic effects of EGTA and LLnL augment rAAV transduction from the apical membrane more than 200fold. Additionally, the conversion of single-stranded viral genomes to linear replication or circular forms has been associated with enhanced AAV transduction by adenoviral early gene products or ultraviolet irradiation, respectively $(12,13,23)$. As shown in Southern blots of Hirt DNA from cultures coinfected with Ad.dl802 and rAAV (Figure 9c, lane 9), LLnL-enhanced AAV transduction was clearly not mediated through the formation of linear replication intermediates (4.7-kb band) as seen in the presence of adenoviral E4orf6 protein produced by Ad.dl802 coinfection.

Ubiquitination of viral capsid proteins after $r A A V$ infection in the airway alters the efficiency of transduction. Proteasomedependent degradation of ubiquitinated molecules represents a major pathway for disposal of both endogenous and foreign proteins (35). Several distinct steps in the regulation of this pathway have been identified, including activation of ubiquitin by its activating enzyme (E1), transfer of the activated ubiquitin to the ubiquitin carrier protein (E2), and subsequent delivery of the activated ubiquitin to the protein substrate by ubiquitin ligase (E3). Ultimately, ubiquitinated proteins are degraded by the $26 \mathrm{~S}$ proteasome through an ATP-dependent process. To test whether enhancement of rAAV transduction by proteasome inhibitor peptides involves liberation of ubiquitinated virus from an endosomal compartment, we first attempted to determine whether ubiquitination of viral capsid indeed occurs. To this end, we sought to examine the extent of ubiquitin side chains on AAV capsid proteins after infection and to determine whether treatment with proteasome inhibitors altered the extent of ubiquitination. AAV capsid proteins were immunoprecipitated using anti-VP 1, 2, and 3 antibody from rAAV-infected human polarized airway cells and human fibroblasts at 6 hours after viral infection. Subsequent Western analysis with antiubiquitin specific antibodies demonstrated a significant increase in the cellular level of ubiquitinated AAV capsid in fibroblasts after proteasome treatment (Figure 10c). Ubiquitination significantly increased the molecular weight of capsid proteins $(63,73$, and $87 \mathrm{kDa})$ to $220-250 \mathrm{kDa}$ and is consistent with the size change after ubiquitination for other molecules (36). Unfortunately, the limited amount of virus retrievable from air-liquid interface-cultured human airway cells precluded our ability to detect ubiquitinated capsid in this system (data not shown). Nonetheless, confluent primary fibroblasts also demonstrated augmentation (tenfold) of transgene expression after treatment with proteasome inhibitors (Figure 10, a and b). From these experiments, we hypothesize that proteasome inhibitors increase rAAV transduction by decreasing the targeting and/or degradation of ubiquitinated AAV in the proteasome. The net result of such proteasome inhibition would be expected to increase the abundance of ubiquitinated viral capsid and is consistent with our observations.
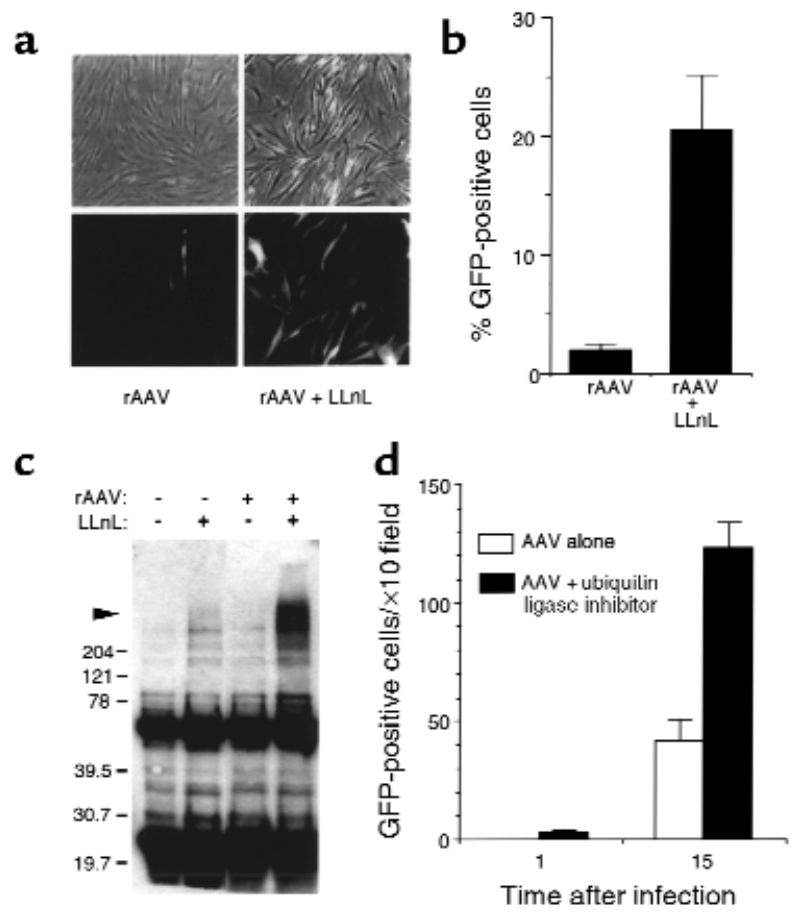

\section{Figure 10}

Modification of the viral ubiquitination state facilitates rAAV transduction. Similar to the polarized human airway cells, rAAV transduction in human primary fibroblasts was also augmented by tripeptide proteasome inhibitors. Human primary fibroblasts were infected with AV.GFP3ori at an moi of 1,000 DNA particles per cell. (a) GFP transgene expression in the absence (left photographs) and presence of 40 $\mu \mathrm{M}$ LLnL (right photographs) at 96 hours after infection. Similar effects were achieved with $4 \mu \mathrm{M}$ Z-LLL (data not shown). Top and bottom panels represent bright-field and FITC-channel fluorescent photomicrographs, respectively. The mean ( $\pm \mathrm{SEM} ; n=3)$ percentage of cells transduced with rAAV, as measured by FACS sorting of GFP expressing cells, is represented in the bar graph of (b). (c) The identification of the ubiquitinated AAV capsid proteins (marked by arrowhead) 6 hours after infection of primary fibroblasts. In this study, rAAV from infected cells was first immunoprecipitated with anti-VP1, 2 , and 3 (AAV-2 capsid) mAb followed by Western blot detection of ubiquitin side chains using an antiubiquitin $m A b$. The two major background bands migrating at approximately 65 and $25 \mathrm{kDa}$ represent heavy and light chain antibody subunits which cross-react with secondary antibodies. Additionally, the equal intensity of lower molecular weight cross-reactive bands (30-40 kDa) serve as internal controls for equal loading of protein. (d) Augmentation of rAAV transduction in polarized airway epithelia by inhibitors of ubiquitin E3 ligase. Epithelia were infected with AV.GFP3ori (10,000 particles per cell) from the basolateral surface after treatment with ubiquitin ligase inhibitor dipeptides (0.2 mM H-Leu-Ala-OH and $0.2 \mathrm{mM} \mathrm{H}$-HisAla-OH). Results demonstrate the mean ( \pm SEM; $n=3)$ number of GFP-expressing cells per $\times 10$ field at 1 and 15 days after infection. 

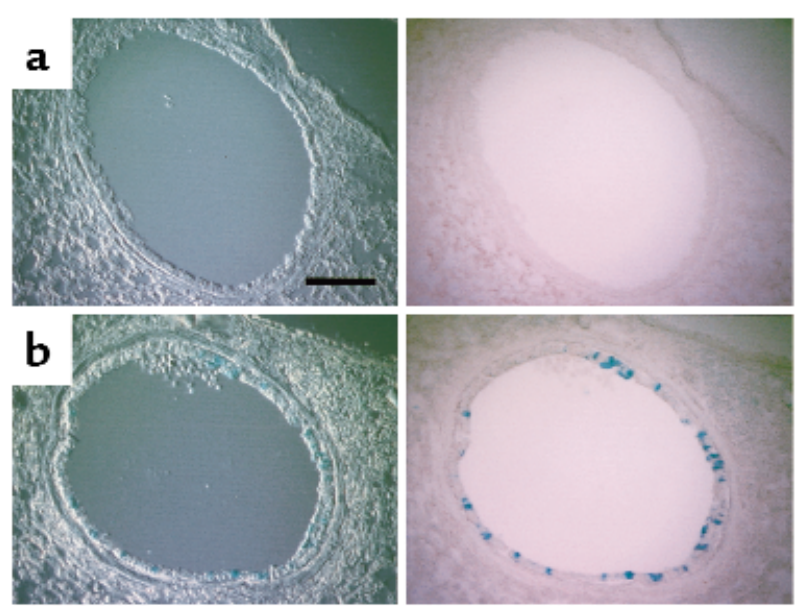

c

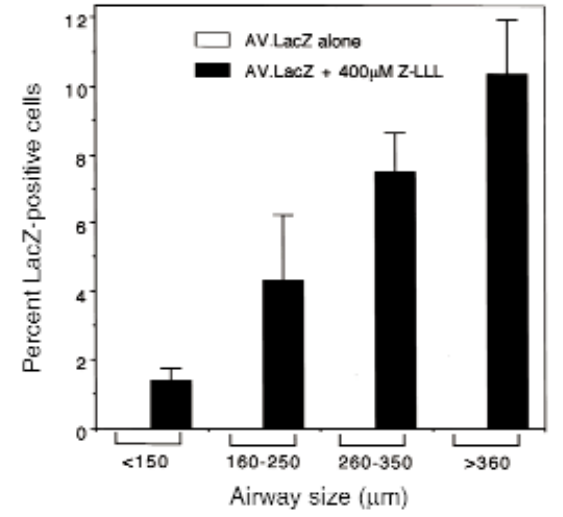

\section{Figure 11}

Persistent induction of rAAV-mediated gene transfer in mouse conducting airways by proteasome inhibitors. Six-week-old BALB/c mice ( $n=3$ animals for each group) were infected with $5 \times 10^{10} \mathrm{DNA}$ particles of AV.LacZ in the absence (a) or presence (b) of $400 \mu \mathrm{M} Z$ Z-LLL by nasal instillation. Representative examples of histochemical staining for LacZ expression in large bronchioles at 150 days after infection are shown in $\mathbf{a}$ and $\mathbf{b}$. The right and left sides of each panel represent Nomarski and bright-field photomicrographs, respectively. The $100-\mu \mathrm{m}$ scale bar applies to all photomicrographs. The mean $( \pm$ SEM) percentage of LacZ-expressing epithelial cells at various levels of the airway was quantitated using the morphometric procedures outlined in the methods, and the analysis represents results from three independent animals for each group (c).

Because a technical limitation in our polarized airway model prevented direct detection of ubiquitinated viral capsid, we sought to determine whether modulation of other steps in the ubiquitin-proteasome pathway could also increase rAAV transduction similarly to that seen with proteasome inhibitors LLnL and Z-LLL. Several dipeptides, such as H-Leu-Ala-OH and H-His-Ala-OH, are known to inhibit ubiquitin ligase E3 (37). Consistent with our hypothesis, application of these ubiquitin ligase inhibitors indeed enhanced rAAV transduction from the basolateral surface of human airway cells (Figure 10d). Taken together, data in both fibroblasts and polarized airway epithelia suggest that AAV capsid is ubiquitinated after endocytosis and that this process is a barrier to rAAV transduction. The most plausible mechanism responsible for the augmentation of rAAV transduction by tripeptide proteasome inhibitors involves the prevention of ubiquitinated virus degradation and/or targeting to the proteasome.

Long-term enhancement of $r A A V$ transduction in lung by proteasome inhibitor in vivo. To evaluate the potential utility of proteasome inhibitors for in vivo gene therapy, we tested both the toxicity and efficacy of these compounds for in vivo $\mathrm{rAAV}$-mediated gene transfer in mouse lung. To assess the toxicity of these proteasome inhibitors in mice, we administrated 10-, 100-, and 1,000-fold higher effective doses of LLnL or Z-LLL than used to induce gene transfer in polarized airway cells, using both intratracheal and systemic (intravenous) delivery. No toxicity was indicated by histological evaluation of the lung and liver (data not shown) or was evidenced by the death of animals. To investigate whether these proteasome inhibitors could improve rAAV transduction in vivo, we delivered AV.LacZ $\left(5 \times 10^{10}\right.$ particles $)$ either alone or in the presence of $400 \mu \mathrm{M} \mathrm{Z}$-LLL by intranasal administration. Mouse lungs were harvested at 3,10 , and 150 days after infection to evaluate shortand long-term effects of the proteasome inhibitor on rAAV transduction. X-gal staining of the lung tissues at 3 and 10 days after infection demonstrated no detectable transgene expression in either proteasome inhibitor-treated or untreated groups (data not shown). In contrast, significant transduction was achieved at 150 days in Z-LLL-treated samples (Figure 11b). Targeted transgene expression was predominantly confined to the conducting airways, rather than in the parenchyma. Alveolar cells were rarely transduced. Although on average only about $5.88 \%$ of airway cells were transduced by AV.LacZ, and LacZ-positive cells were observed throughout the entire conducting airway, a characteristic transduction profile was evident. The transduction efficiency in larger bronchioles (> $350 \mu \mathrm{m})$ reached a mean of $10.36 \pm 1.63 \%$ of the airway epithelium, whereas $1.37 \pm 0.41 \%$ of airway cells in the smaller bronchioles $(<150 \mu \mathrm{m})$ expressed the $\beta$-galactosidase transgene (Figure 11c). The range of transgene expression in distal and proximal airways was $0-4 \%$ and $5-18 \%$, respectively. This transduction profile demonstrating a higher and more consistent transduction in larger airways likely reflects a more uneven delivery of virus to regions of the lung encompassing the smaller airways. Examination of cryosections from lungs infected by AV.LacZ alone revealed only two LacZ-positive cells in a total of 315 airway sections ( $n=3$ animals).

Proteasome inbibitors also facilitate $r A A V$-mediated gene transfer in liver, but not in muscle. It has been previously shown that AAV transduction in certain tissues such as muscle and retina is very efficient $(16,38)$, whereas other tissues including lung and liver are less favorably transduced $(6,39)$. Several factors could account for the variations in rAAV organ/tissue tropism. In addition to the abundance and distribution of the AAV receptor and/or coreceptors, differences in intracellular processing of the endocytosed virus might also affect AAV-mediated gene 

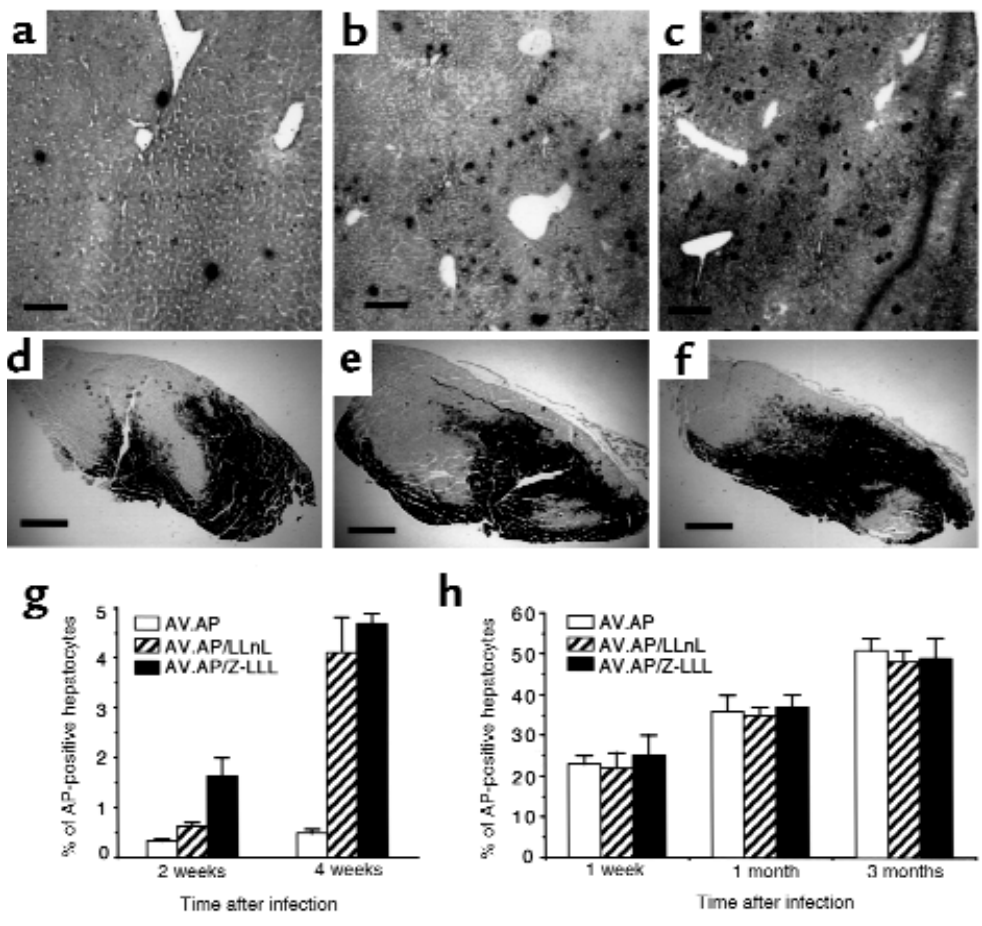

h

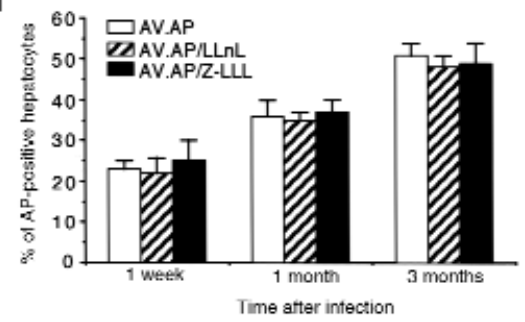

Figure 12

Proteasome inhibitors augment rAAV transduction in liver, but not in muscle. The effect of proteasome inhibitors on rAAV-mediated gene transfer in liver was examined by portal vein administration of AV.Alkphos in the presence or absence of proteasome inhibitors. Representative photomicrographs of histochemical staining for AP in liver sections at 4 weeks after infection are shown in a (rAAV alone), $\mathbf{b}(r A A V+200 \mu \mathrm{M}$ LLnL), and $\mathbf{c}(r A A V+40 \mu M$ Z-LLL). The scale bars in panels $\mathbf{a}, \mathbf{b}$, and $\mathbf{c}$ are $50 \mu \mathrm{m}$. rAAV-mediated gene transfer in mouse anterior tibialis muscle was evaluated at 1 week, 1 month, and 3 months after infection with AV.Alkphos. Representative photomicrographs of histochemical staining for AP in whole muscle cross-sections at 3 months after infection are shown in $\mathbf{d}$ (rAAV alone), e (rAAV+200 $\mu \mathrm{M} L L n L)$, and $\mathbf{f}$ ( $r A A V+40 \mu \mathrm{M} Z$-LLL). The scale bars in $\mathbf{d}, \mathbf{e}$, and $\mathbf{f}$ are $500 \mu \mathrm{m}$. (g) Mean ( \pm SEM) percentage of AP-positive hepatocytes ( $n=3$ animals for each experimental condition, averaged for all six lobes in each animal). (h) Mean ( \pm SEM) percentage of AP-positive myofibers at different times after infection $(n=4$ muscle samples for each experimental condition). delivery. Results thus far have indicated that inefficient endosomal processing represents a major barrier for gene transfer in airway epithelia and that this limitation can be overcome by transient treatment with proteasome inhibitors. To extend further our findings in lung, we also examined the effect of the proteasome inhibitors on liver and muscle. As shown in Figure 12, rAAV alone resulted in only limited transduction in mouse liver, averaging less than $0.5 \%(0.49 \pm 0.07 ; n=3)$ of hepatocytes expressing the heat-resistant alkaline phosphatase transgene (Figure 12, a and g). In contrast, coadministration of proteasome inhibitors LLnL or Z-LLL with the virus significantly augmented gene transfer by 4 weeks after infection to an average of $5 \%$ hepatocytes (Figure $12, \mathrm{~b}, \mathrm{c}$, and g). In certain lobes of the liver, the level of AP expression with this vector reached $10 \%$ of hepatocytes in the presence of proteasome inhibitors. Despite findings that proteasome inhibitors augmented AAV transduction in both lung and liver, coadministration of proteasome inhibitors did not augment AAV-mediated gene transfer in either skeletal or cardiac muscle. Quantitative analysis of AAV transduction in mouse skeletal muscles (Figure 12, d-f and h) and rat cardiac muscles (data not shown) demonstrated that neither the kinetics nor the level of AAV transduction was affected. Taken together, these results suggest that ubiquitination and endosomal processing barriers to $\mathrm{AAV}-2$ transduction are likely to be organ specific and could explain the organ-specific tropisms observed with this virus.

\section{Discussion}

Inefficient gene transfer from the apical surface of the airway has been a major obstacle in numerous gene therapy approaches for cystic fibrosis utilizing recombinant adenovirus (2), adeno-associated virus (6), and retrovirus (1). It has been generally thought that inefficient viralmediated gene delivery through the apical membrane of airway epithelia is predominantly due to the lack of receptors or coreceptors on this surface. In this report, we have attempted to define more clearly potential barriers responsible for the inefficient apical transduction by rAAV-2 in the airway and have generated several potentially useful strategies to overcome these barriers.

Molecular analysis of rAAV infection in polarized airway epithelia has revealed several unique findings. First, we have provided conclusive evidence that the previously reported lack of known AAV-2 receptor and coreceptors (7) at the apical membrane of airway epithelia does not abrogate AAV infection. Although transduction (as determined by transgene expression) from the basolateral surface is 200 -fold more efficient than from the apical membrane, quantitative and semiquantitative analyses of viral endocytosis with either [ $\left.\mathrm{S}^{35}\right]$-labeled virus or Southern blotting have demonstrated that viral uptake from the apical surface is only two- to sevenfold less efficient than from the basolateral membrane. Therefore, it is reasonable to assume that a previously unidentified alternative receptor/coreceptors and/or receptor-independent mechanism(s) might be involved in AAV uptake from the mucosal surface of the airway.

Polarity is widely recognized to significantly influence endosomal processing of many proteins, and distinct sorting mechanisms have been described for the apical and basolateral compartments (40). The lack of a direct correlation between the efficiency of viral uptake and transgene expression after basolateral and apical infection suggests that additional postendocytic barriers exist for rAAV-mediated gene transfer. Dif- 
ferences in the extent of AAV nuclear trafficking after basolateral versus apical routes of infection suggest that basal and apical cellular compartments possess distinct biologic properties that may influence the polarity of AAV transduction. Endosomal processing barriers to $\mathrm{HAAV}$ transduction may not be limited to polarized epithelial cells. In support of this notion, a recent report described impaired intracellular trafficking of viral particles to the nucleus in NIH 3T3 cells (41). Our laboratory has also shown that rAAV can remain in an inactive state for as long as 7 days in confluent primary fibroblast cells until rescued by ultraviolet irradiation to a functionally active state (42). Taken together, our present studies, and both of these recent reports, support the hypothesis that postendocytic barriers to infection exist in multiple cell types. However, the etiology of this barrier has remained elusive.

In the airway, the major rate-limiting steps in $\mathrm{rAAV}$ transduction from the mucosal surface appear to involve inefficient endosomal processing of the internalized virus. Regulated intracellular proteolysis through proteasomes plays a critical role in many physiological and pathological conditions (35). Additionally, the proteasome has been suggested to have antiviral functions in HIV infection (29), implying that the inhibition of proteasome function could be beneficial in promoting transduction with recombinant viruses. Based on the molecular evidence that apical infection of $\mathrm{AAV}$ in the airway is significantly limited by postentry events, we currently hypothesize that ubiquitin/proteasome pathways are instrumental in this blockage. The proteasome is commonly known as a compartment for clearance of endogenous and foreign proteins. However, recent studies also suggested that the proteasome system is involved in regulating endocytosis (43). Our results clearly demonstrate that rAAV-mediated gene transfer to the airway epithelia is also significantly enhanced by proteasome inhibitors. Furthermore, this enhancement is correlated with proteasome inhibitor-stimulated viral trafficking to the nucleus. Although proteasome inhibitors increased longterm levels of AAV transduction from the apical surface, their effect on basolateral infection appeared predominantly to alter the rate, rather than the long-term levels, of transduction. These differences highlight fundamentally distinct pathways involved in rAAV transduction from the apical and basolateral surfaces.

Several findings also support the notion that ubiquitination of virus after endocytosis may be a critical mechanism for sorting incoming AAV. First, treatment of airway epithelia with proteasome inhibitors known to block ubiquitin-dependent degradation of proteins enhances rAAV gene transfer. Second, inhibition of ubiquitin E3 ligase activity in airway epithelia also enhances transduction. Last, we have demonstrated that rAAV capsid proteins are ubiquitinated after infection in human fibroblasts and that the extent of this ubiquitination is increased by inhibition of ubiquitin-proteasome-degradative pathways (Figure 10).
From an applied standpoint, one of the most important findings in this study is the persistent high-level rAAV transduction induced by proteasome inhibitor in mouse lung. Coadministration of Z-LLL with rAAV increased transgene expression from undetectable levels to $10.36 \pm 1.63 \%$ of proximal bronchial epithelial cells at 150 days after infection. The feasibility of this strategy for clinical application is further supported by the lack of a detectable local or systemic toxicity after proteasome inhibitor administration to mice. Furthermore, preliminary studies in several other organs have suggested that ubiquitination of rAAV2 may occur in an organ-specific fashion. The application of proteasome inhibitors in skeletal and cardiac muscle had no effect on either shortterm or long-term rAAV-mediated gene transfer. However, the liver demonstrated a tenfold enhancement in rAAV transduction in the presence of proteasome inhibitors by 4 weeks after infection. These findings suggest that tripeptide proteasome inhibitors could be used to increase gene transfer in organs other than the lung, depending on the cell biology of virus processing.

In conclusion, we have demonstrated that a significant barrier to apical infection in the airway with rAAV-2 lies at the level of endosomal processing and ubiquitination. Modulation of the ubiquitin-proteasome system has revealed innovative strategies to enhance rAAV transduction from the mucosal surface of the airway for gene therapy of cystic fibrosis. Modulation of these pathways may also be beneficial in rAAV-2-mediated gene delivery to other organs where the ubiquitin-proteasome system is a substantial barrier to transduction.

\section{Acknowledgments}

This work was supported by the National Institutes of Health (grant RO1 HL58340 to J.F. Engelhardt) and a pilot grant (DK54759 to D. Duan) of the Gene Therapy Center for Cystic Fibrosis and Other Genetic Diseases from the National Institutes of Health and Cystic Fibrosis Foundation. We also gratefully acknowledge P. Karp and P. Weber of the Gene Therapy Center Cells and Tissue Core (DK54759), the University of Iowa DERC (NIDDK) for tissue culture media supplies, and T. Ritchie for editorial assistance in the preparation of this manuscript.

\footnotetext{
1. Wang, G., et al. 1998. Efficient gene transfer to differentiated human airway epithelia with recombinant amphotropic and xenotropic retroviruses. J. Virol. 72:9818-9826.

2. Zabner, J., Freimuth, P., Puga, A., Fabrega, A., and Welsh, M.J. 1997. Lack of high affinity fiber receptor activity explains the resistance of ciliated airway epithelia to adenovirus infection. J. Clin. Invest. 100:1144-1149.

3. Summerford, C., and Samulski, R.J. 1998. Membrane-associated heparan sulfate proteoglycan is a receptor for adeno-associated virus type 2 virions. J. Virol. 72:1438-1445.

4. Qing, K., et al. 1999. Human fibroblast growth factor receptor 1 is a coreceptor for infection by adeno-associated virus 2. Nat. Med. 5:71-77.

5. Summerford, C., Bartlett, J.S., and Samulski, R.J. 1999. AlphaVbeta5 integrin: a co-receptor for adeno-associated virus type 2 infection. Nat. Med. 5:78-82.

6. Duan, D., Yue, Y., Yan, Z., McCray, P.B., and Engelhardt, J.F. 1998. Polarity influences the efficiency of recombinant adenoassociated virus infection in differentiated airway epithelia. Hum. Gene Ther. 9:2761-2776.

7. Duan, D., Yue, Y., and Engelhardt, J.F. 1999. Response to "Polarity influences the efficiency of recombinant adenoassociated virus infection in
} 
differentiated airway epithelia." Hum. Gene Ther. 10:1553-1557.

8. Teramoto, S., et al. 1998. Factors influencing adeno-associated virusmediated gene transfer to human cystic fibrosis airway epithelial cells: comparison with adenovirus vectors. J. Virol. 72:8904-8912.

9. Qing, K., et al. 1997. Adeno-associated virus type 2-mediated transfer of ecotropic retrovirus receptor cDNA allows ecotropic retroviral transduction of established and primary human cells. J. Virol. 71:5663-5667.

10. Wickham, T.J., Roelvink, P.W., Brough, D.E., and Kovesdi, I. 1996. Adenovirus targeted to heparan-containing receptors increases its gene delivery efficiency to multiple cell types. Nat. Biotechnol. 14:1570-1573.

11. Bartlett, J.S., Kleinschmidt, J., Boucher, R.C., and Samulski, R.J. 1999. Targeted adeno-associated virus vector transduction of nonpermissive cells mediated by a bispecific F(ab'gamma) 2 antibody. Nat. Biotechnol. 17:181-186.

12. Fisher, K.J., et al. 1996. Transduction with recombinant adeno-associated virus for gene therapy is limited by leading-strand synthesis. J. Virol. 70:520-532.

13. Sanlioglu, S., Duan, D., and Engelhardt, J.F. 1999. Two independent molecular pathways for recombinant adeno-associated virus genome conversion occur after UV-C and E4orf6 augmentation of transduction. Hum. Gene Ther. 10:591-602.

14. Zabner, J., Wadsworth, S.C., Smith, A.E., and Welsh, M.J. 1996. Adenovirus-mediated generation of cAMP-stimulated Cl-transport in cystic fibrosis airway epithelia in vitro: effect of promoter and administration method. Gene Ther. 3:458-465.

15. Duan, D., Fisher, K.J., Burda, J.F., and Engelhardt, J.F. 1997. Structural and functional heterogeneity of integrated recombinant AAV genomes. Virus Res. 48:41-56.

16. Duan, D., et al. 1998. Circular intermediates of recombinant adeno-associated virus have defined structural characteristics responsible for long term episomal persistence in muscle. J. Virol. 72:8568-8577.

17. Yang, J., et al. 1999. Concatamerization of adeno-associated viral circular genomes occurs through intermolecular recombination. J. Virol. 73:9468-9477.

18. Samulski, R.J., Chang, L.S., and Shenk, T. 1987. A recombinant plasmid from which an infectious adeno-associated virus genome can be excised in vitro and its use to study viral replication. J. Virol. 61:3096-3101.

19. Duan, D., et al. 1999. Dynamin is required for recombinant adeno-associated virus type 2 infection. J. Virol. 73:10371-10376.

20. Duan, D., Sehgal, A., Yao, J., and Engelhardt, J.F. 1998. Lef1 transcription factor expression defines airway progenitor cell targets for in utero gene therapy of submucosal gland in cystic fibrosis. Am. J. Respir. Cell Mol. Biol. 18:750-758.

21. Walters, R.W., Duan, D., Engelhardt, J.F., and Welsh, M.J. 2000. Incorporation of adeno-associated virus in a calcium phosphate coprecipitate improves gene transfer to airway epithelia in vitro and in vivo. J. Virol. 74:535-540.

22. Hughes, S.E., and Hall, P.A. 1993. Immunolocalization of fibroblast growth factor receptor 1 and its ligands in human tissues. Lab. Invest. 69:173-182.

23. Duan, D., et al. 1999. Formation of adeno-associated virus circular genomes is differentially regulated by adenovirus E4 ORF6 and E2a gene expression. J. Virol. 73:161-169.

24. Alexander, I.E., Russell, D.W., and Miller, A.D. 1994. DNA-damaging agents greatly increase the transduction of nondividing cells by adeno- associated virus vectors. J. Virol. 68:8282-8287.

25. Russell, D.W., Alexander, I.E., and Miller, A.D. 1995. DNA synthesis and topoisomerase inhibitors increase transduction by adeno-associated virus vectors. Proc. Natl. Acad. Sci. USA. 92:5719-5723.

26. Qing, K., et al. 1997. Role of tyrosine phosphorylation of a cellular protein in adeno-associated virus 2-mediated transgene expression. Proc. Natl. Acad. Sci. USA. 94:10879-10884.

27. Mah, C., et al. 1998. Adeno-associated virus type 2 -mediated gene transfer: role of epidermal growth factor receptor protein tyrosine kinase in transgene expression. J. Virol. 72:9835-9843.

28. Sanlioglu, S., and Engelhardt, J. 1999. Cellular redox state alters recombinant adeno-associated virus transduction through tyrosine phosphatase pathways. Gene Ther. 6:1427-1437.

29. Schwartz, O., Marechal, V., Friguet, B., Arenzana-Seisdedos, F., and Heard, J.M. 1998. Antiviral activity of the proteasome on incoming human immunodeficiency virus type 1.J. Virol. 72:3845-3850.

30. Rock, K.L., et al. 1994. Inhibitors of the proteasome block the degradation of most cell proteins and the generation of peptides presented on MHC class I molecules. Cell. 78:761-771.

31. Fenteany, G., et al. 1995. Inhibition of proteasome activities and subunitspecific amino-terminal threonine modification by lactacystin. Science. 268:726-731.

32. Rubin, D.M., and Finley, D. 1995. Proteolysis. The proteasome: a protein-degrading organelle? Curr. Biol. 5:854-858.

33. Jensen, T.J., et al. 1995. Multiple proteolytic systems, including the proteasome, contribute to CFTR processing. Cell. 83:129-135.

34. Everett, R.D., Orr, A., and Preston, C.M. 1998. A viral activator of gene expression functions via the ubiquitin-proteasome pathway. EMBO J. 17:7161-7169.

35. Schwartz, A.L., and Ciechanover, A. 1999. The ubiquitin-proteasome pathway and pathogenesis of human diseases. Annu. Rev. Med. 50:57-74.

36. Bregman, D.B., et al. 1996. UV-induced ubiquitination of RNA polymerase II: a novel modification deficient in Cockayne syndrome cells. Proc. Natl. Acad. Sci. USA. 93:11586-11590.

37. Obin, M., et al. 1999. Neurite outgrowth in PC12 cells. Distinguishing the roles of ubiquitylation and ubiquitin-dependent proteolysis. J. Biol. Chem. 274:11789-11795.

38. Bennett, J., Duan, D., Engelhardt, J.F., and Maguire, A.M. 1997. Realtime, noninvasive in vivo assessment of adeno-associated virus-mediated retinal transduction. Invest Ophthalmol. Vis. Sci. 38:2857-2863.

39. Xiao, W., et al. 1998. Adeno-associated virus as a vector for liver-directed gene therapy. J. Virol. 72:10222-10226.

40. Odorizzi, G., Pearse, A., Domingo, D., Trowbridge, I.S., and Hopkins, C.R. 1996. Apical and basolateral endosomes of MDCK cells are interconnected and contain a polarized sorting mechanism. J. Cell Biol. 135:139-152.

41. Hansen, J., Qing, K., Kwon, H.J., Mah, C., and Srivastava, A. 2000. Impaired intracellular trafficking of adeno-associated virus type 2 vectors limits efficient transduction of murine fibroblasts. J. Virol. 74:992-996.

42. Sanlioglu, S., Benson, P., and Engelhardt, J.F. 2000. Loss of ATM function enhances recombinant adeno-associated virus transduction and integration through pathways similar to UV irradiation. Virology. 268:68-78.

43. Strous, G.J., and Govers, R. 1999. The ubiquitin-proteasome system and endocytosis. J. Cell Sci. 112:1417-1423. 